Estudios Constitucionales, Año 14, No 2, 2016, pp. 305-346

ISSN 07180195

Centro de Estudios Constitucionales de Chile Universidad de Talca

"El estándar del derecho de aguas desde la perspectiva

del derecho internacional de los derechos humanos y del medio ambiente"

Oscar Recabarren Santibáñez

\title{
EL ESTÁNDAR DEL DERECHO DE AGUAS DESDE LA PERSPECTIVA DEL DERECHO INTERNACIONAL DE LOS DERECHOS HUMANOS Y DEL MEDIO AMBIENTE*
}

\author{
Water Law Standard from the Perspective \\ of the InTERnATIONAL LAW OF Human Rights and ENVIRONMENT
}

\author{
Oscar Recabarren SantibáNÉEZ \\ Universidad Academia de Humanismo Cristiano \\ recabarrenoscar@gmail.com
}

RESUMEN: El presente trabajo persigue identificar la pauta que el Derecho Internacional de los Derechos Humanos y del Medio Ambiente entrega al Estado para la adecuada configuración de su Derecho de Aguas. De esta forma, se analiza la relación conceptual entre los derechos humanos y el medio ambiente, asi como los aspectos más relevantes del derecho humano al agua y al saneamiento. Asimismo, se estudian los principios establecidos por el Derecho Internacional para una adecuada gestión de los recursos hidricos como garantía del derecho humano al agua y al saneamiento.

ABSTRACT: The following article aims to identify the guidelines that the International Law of Human Rights and Environment gives to the State for the appropriate configuration of its Water Law. This paper analyzes the conceptual relation between human rights and environment, and also the most relevant aspects of the human right to water and sanitation. Additionally, it studies the principles established by the International Law for a right management of water resources as a guarantee of the human right to water and sanitation.

PALABRAS CLAVE: Derecho de aguas, Derecho humano al agua y al saneamiento, Derecho ambiental, derechos humanos.

KEYWORDS: Water law, Human right to water and sanitation, Environmental law, Human rights.

\section{INTRODUCCIÓN}

A través de sus respectivas legislaciones, los Estados regulan con cierta libertad los diversos aspectos relacionados con los recursos hídricos. Así, determinan la

\footnotetext{
* Trabajo recibido el 2 de febrero de 2016 y aprobado el 7 de septiembre de 2016.

** Licenciado en Ciencias Jurídicas por la Universidad del Desarrollo. Máster en Derecho Ambiental por la Universitat Rovira i Virgili (España). Diplomado en Introducción al Derecho Internacional de los Derechos Humanos por la Universidad de Chile. Magíster en Derecho Internacional de los Derechos Humanos por la Universidad Diego Portales. Profesor de Derecho Internacional Público de la Universidad Academia de Humanismo Cristiano.
} 
titularidad pública de las aguas, reglan el acceso de los particulares a este recurso, definen una planificación hidrológica, crean organismos y les asignan funciones. A este respecto, el Derecho Internacional, especialmente en el ámbito de los derechos humanos y del medio ambiente, establece múltiples obligaciones que directa o indirectamente condicionan la regulación nacional de aguas, fijándole al Estado un margen a sus facultades discrecionales, y cuyo incumplimiento puede hacerlo incurrir en responsabilidad internacional.

Así, el presente trabajo se centra en las aguas como elemento del medio ambiente y como derecho humano, teniendo por finalidad determinar el estándar que el Derecho Internacional fija al Estado para una configuración de su legislación hídrica que le permita garantizar el cumplimiento de los derechos humanos y la protección del medio ambiente.

De este modo, en la primera parte del estudio se hace alusión al vínculo conceptual entre el bien jurídico medio ambiente y los demás derechos humanos, así como a la existencia y al rango jurídico del derecho a un medio ambiente adecuado. Lo anterior permitirá entregar las obligaciones generales de la normativa internacional y las razones por las cuales éstas deben ser incorporadas en las legislaciones de aguas estatales.

A su vez, en la segunda parte se examinan los asuntos más importantes del reconocimiento del derecho humano al agua y al saneamiento, su estatus jurídico y su contenido, las obligaciones derivadas de dicho reconocimiento y su dimensión ambiental. Asimismo, se analizan los principios esenciales del Derecho Internacional referentes a la gestión sustentable de los recursos hídricos, lo que finalmente entregará el estándar internacional en materia de derechos humanos y medio ambiente.

\section{LOS DIVERSOS ENFOQUES DE LA RELACIÓN CONCEPTUAL}

ENTRE EL MEDIO AMBIENTE Y LOS DERECHOS HUMANOS

Esta primera parte pretende determinar aquellas obligaciones de derechos humanos que por estar relacionadas con el disfrute, de un medio ambiente adecuado, constituyen una exigencia general para el Derecho de Aguas doméstico.

Para ello, se examinan las diversas perspectivas en las que el bien jurídico medio ambiente se relaciona con los demás derechos humanos, así como también la existencia y el estatus jurídico del ambiente adecuado como derecho humano autónomo ${ }^{1}$.

1 Por medio ambiente adecuado se entenderá también cualquier otra denominación similar, tales como medio ambiente sano, sin riesgos, limpio, saludable, libre de contaminación, entre otras. 


\section{El medio ambiente como conditio sine qua non de los derechos humanos}

Existe un reconocimiento unánime por parte de la doctrina de que el deterioro ambiental puede significar la violación de una serie de derechos fundamentales como la vida, la salud, el derecho al agua y al saneamiento, a la alimentación, a la vivienda adecuada, a la vida privada y familiar, a la libre determinación e incluso a la propiedad ${ }^{2}$. De este modo, se entiende que el daño ambiental entorpece a los Estados en su tarea de garantizar el goce pleno y efectivo de los derechos humanos ${ }^{3}$.

Por consiguiente, un primer enfoque hace alusión al medio ambiente como un requisito sine qua non para el disfrute de otros derechos humanos catalogados de sustantivos, lo cual se ha expresado en numerosos instrumentos internacionales y por distintos órganos de promoción y protección de los derechos humanos, los cuales se analizan a continuación.

\subsection{Algunos instrumentos internacionales referentes al carácter adjetivo del medio ambiente}

En múltiples conferencias internacionales, la comunidad internacional se ha referido al medio ambiente como presupuesto indispensable para el cumplimiento de otros derechos. No obstante, los Estados no siempre se han centrado exclusivamente en los derechos humanos como fundamento de la protección ambiental, sino que el vínculo entre ambos bienes jurídicos ha ido evolucionando de la mano de otros conceptos, como el del desarrollo sustentable, el derecho al desarrollo y el derecho de las generaciones futuras.

Fue en la Declaración de la Conferencia de Naciones Unidas sobre Medio Ambiente Humano, adoptada en Estocolmo en 1972, cuando por primera vez se hace alusión a la transcendencia del nexo entre la protección del medio ambiente y el goce pleno y efectivo de los derechos humanos, manifestando, además, el deber de los Estados de garantizar los derechos de las generaciones futuras.

Dos décadas más tarde, la Declaración de la Conferencia de Naciones Unidas sobre Medio Ambiente y Desarrollo, adoptada en Río de Janeiro, establece importantes principios en la materia y afirma que la persona humana constituye el eje central de las decisiones encaminadas hacia el desarrollo sustentable, reconociendo

2 Bruzón y Antúnez (2012), p. 77; Ferreira (2008), pp. 146-148; Simón (2010), p. 91; Shelton (2010), p. 127; LEWIS (2012), pp. 38-40; BORRÀs (2014), p. 653.

3 LEWIS (2012), p. 40. 
explícitamente "... el derecho a una vida saludable y productiva en armonía con la naturaleza” (principio 1$)^{4}$.

$\mathrm{Al}$ año siguiente, con la Declaración de la Conferencia Mundial de Derechos Humanos, adoptada en Viena, los Estados sostienen que el derecho al desarrollo debe cumplirse de manera equitativa con las necesidades del medio ambiente, tanto de las generaciones presentes como de las futuras. Igualmente, admiten que el vertido y desecho de sustancias tóxicas pueden generar un riesgo grave para el derecho a la vida y la salud (párrafo 11).

Por último, cabe hacer mención al Informe final de la Relatora Especial Fatma Zohra Ksentini sobre los Derechos Humanos y el Medio Ambiente, presentado a la entonces Comisión de Derechos Humanos de Naciones Unidas en 1994. En este documento, se fortalece la idea de que los daños ambientales perjudican directamente el goce de un gran número de derechos humanos (párrafo 248) y que la violación de alguno de estos derechos afecta al medio ambiente (párrafo 250).

En resumen, diversos instrumentos internacionales ponen de manifiesto la obligación de los Estados de garantizar una adecuada protección del medio ambiente, toda vez que la composición física del mismo -entorno materialconstituye el presupuesto básico para el pleno goce y ejercicio de una serie de derechos humanos.

\subsection{Las decisiones de los órganos internacionales de carácter jurisdiccional y cuasi jurisdiccional}

En el ámbito de la Corte Internacional de Justicia, destacada es la opinión del entonces vicepresidente Sr. Weeramantry, quien hace referencia a la protección ambiental como una pieza crucial en el discurso de los derechos humanos, pues, a su juicio, de ella depende el goce de múltiples derechos, como el derecho a la vida y la salud5.

\footnotetext{
4 Si bien la Declaración de Río tampoco constituye un instrumento jurídico vinculante, igualmente ha servido de impulso para que distintos convenios internacionales integren las exigencias instrumentales de información, participación y acceso a la justicia en materia ambiental (principio 10). PIGRAU y Borràs (2008), p. 25. Es el caso del Convenio sobre la Diversidad Biológica de 1992 (artículo 1), la Convención Marco sobre el Cambio Climático de 1992 (artículo 1) y la Convención de Lucha Contra la Desertificación a los Países Afectados por la Sequía Grave y/o la Desertificación, en Particular África, de 1994 (artículo 2).

5 Corte Internacional de Justicia, Hungría con Eslovaquia (1997), pp. 88-92. En el mismo sentido, SHELTON (2010), p. 112.
} 
Ahora bien, los distintos órganos universales y regionales de promoción y protección de los derechos humanos se han pronunciado sobre este vínculo en numerosas oportunidades ${ }^{6}$.

En el sistema americano, si bien la Convención Americana de Derechos Humanos (en adelante, $\mathrm{CADH}$ ) no hace referencia al bien jurídico medio ambiente, la Comisión Interamericana de Derechos Humanos (en adelante, $\mathrm{CIDH}$ ) ha señalado que una legislación deficiente o el incumplimiento de una normativa adecuada pueden provocar un deterioro ambiental que signifique la violación de otros derechos humanos tutelados por la $\mathrm{CADH}^{7}$. Mientras tanto, la Corte Interamericana de Derechos Humanos (en adelante, Corte IDH) ha reconocido expresamente la existencia de un vínculo innegable entre la protección del medio ambiente y el disfrute de otros derechos humanos ${ }^{8}$.

Por su parte, el Convenio Europeo para la Protección de los Derechos Humanos y de las Libertades Fundamentales de 1950 (en adelante, CEDH) tampoco consagra expresamente el derecho a un medio ambiente adecuado. No obstante, el Tribunal Europeo de Derechos Humanos (en adelante, TEDH) en numerosas sentencias ${ }^{9}$, ha desarrollado una interpretación evolutiva del $\mathrm{CEDH}$ para reconocer la protección ambiental, a través del derecho a la vida (artículo 2) y, particularmente, del derecho a la vida privada y familiar (artículo 8.1) ${ }^{10}$.

6 En el ámbito universal, véanse Comité de Derechos Económicos, Sociales y Culturales (1999), párrafos 4 y 10; y (2000), párrafo 15.

7 Comisión Interamericana de Derechos Humanos (1997).

8 Corte Interamericana de Derechos Humanos, Luna López con Honduras (2013), párrafo 123.

9 Tribunal Europeo de Derechos Humanos, López Ostra con España (1994), Guerra con Italia (1998), Hatton con Reino Unido (2003), Fadeyeva con Rusia (2005), Dubetska y otros con Ucrania (2011), y Bor con Hungría (2013).

10 El TEDH considera al CEDH como un instrumento constitucional de orden público europeo, pues expresa los principios fundamentales de una sociedad, donde su aplicación no debe estar confinada a la resolución de los problemas específicos que dieron lugar a su dictación. BONINE y KRAVCHENKO (2012), pp. 24-26. A su vez, la protección jurídica del TEDH es calificada como una defensa cruzada de derechos, en virtud de la cual a través de la protección de ciertos derechos y libertades, que sí se encuentran incluidos en el CEDH, se pueden alcanzar innegables impactos en la protección del medio ambiente. Lo cual podría lograrse ya sea por medio del derecho a la justicia, del derecho a la intimidad y a la protección del domicilio, de la defensa de la propiedad, u otros. MarTín-Retortillo, L. (2008), p. 781. Por su parte, la interpretación dinámica del artículo 8.1 del CEDH ha sido la principal impulsora del reconocimiento de obligaciones protectoras del medio ambiente, jugando un rol importante en la amplitud del concepto de vida privada, SIMÓN (2010), p. 87. 
Así, y en razón del rol adjetivo del bien jurídico medio ambiente en relación con otros derechos humanos, cada Estado se encuentra obligado a configurar su ordenamiento jurídico -incluida su legislación hídrica- en base a todas las consideraciones necesarias para permitir una óptima conservación ambiental.

En consecuencia, el Derecho de Aguas debe estar destinado a garantizar que el aprovechamiento de los recursos hídricos no constituya una afectación para el medio ambiente, que signifique o pueda significar una violación de otros derechos fundamentales, como el derecho humano al agua y al saneamiento. En caso contrario, el respectivo Estado estaría, eventualmente, incumpliendo con sus obligaciones y, en consecuencia, afecto a responsabilidad internacional. Asimismo, la sociedad civil puede aprovechar todos los mecanismos internacionales establecidos para la defensa de los derechos humanos que pudieran verse afectados por la degradación ambiental ${ }^{11}$.

De la misma manera, la ciudadanía puede valerse de los derechos humanos cuyo ejercicio permite la protección de otros derechos, y cuyo vínculo se analiza a continuación.

\section{Los derechos humanos procedimentales como instrumento de protección del medio ambiente}

Una segunda perspectiva hace referencia a la enorme trascendencia que el ejercicio de ciertos derechos, como la libertad de expresión y de asociación, la educación y, particularmente, el acceso a la información, la participación pública en la toma de decisiones, y el acceso a la justicia y recursos efectivos, importa para la protección jurídica del medio ambiente.

Es importante tener en cuenta que cuando el ejercicio de los derechos procedimentales es maximizado, la autoridad se encuentra en una mejor posición para conducir las políticas ambientales y, asimismo, existen más posibilidades para que la sociedad civil exija una mayor protección ambiental ${ }^{12}$. En conformidad con

11 En todo caso, la judicialización de los conflictos ambientales tendría su origen, generalmente, en la afectación de ciertos derechos civiles y políticos o en la vulneración de los derechos procedimentales, siendo inusual la aducción de los derechos económicos, sociales y culturales, en razón de su problemática protección judicial. Courtis (2007), pp. 80 y 81, y Ortega y Larraín (2012), pp. 535 y 546.

12 En este sentido, Informe preliminar del Experto independiente John H. Knox sobre la cuestión de las obligaciones de derechos humanos relacionadas con el disfrute de un medio ambiente sin riesgos, limpio, saludable y sustentable. Consejo de Derechos Humanos (2012), pp. 10 y 11, y Lewis (2012), p. 40. 
los principios de indivisibilidad, interrelación e interdependencia, se entiende que estos derechos procedimentales constituyen un mecanismo de garantía para el bien jurídico medio ambiente, siendo la piedra angular de una democracia ambiental, alcanzada únicamente por la anuencia de la ciudadanía en la adopción de las decisiones ambientales ${ }^{13}$.

En el ámbito universal, el Convenio No 169 de la Organización Internacional del Trabajo (en adelante, OIT) consagra la participación como el complemento del derecho de los pueblos indígenas a la tierra, al territorio y los recursos naturales, estableciéndose que estos pueblos tienen derecho a participar en la utilización, administración y conservación de los recursos naturales (artículo 15).

En el sistema interamericano, tanto la CIDH como la Corte IDH han hecho alusión a la trascendental importancia de los derechos de acceso a la información, participación y acceso a la justicia en materia ambiental. Así, en los casos en que el Estado respectivo ha entregado concesiones para el desarrollo de actividades económicas que puedan causar un impacto ambiental, en general, e hídrico, en particular, la CIDH ha dejado en claro la obligación de los Estados de "consultar en forma previa, plena, libre e informada" a la sociedad civil ${ }^{14}$.

Igualmente, la Corte IDH ha sostenido que, para asegurar una participación efectiva en los planes de desarrollo e inversión, el Estado debe entregar la información pertinente, que posibilite a la comunidad tomar conocimiento de los eventuales riesgos para el medio ambiente y la salud de la población. Asimismo, se exige que el Estado consulte activamente a las comunidades indígenas, según sus propias costumbres y tradiciones, desde las primeras etapas de los proyectos ${ }^{15}$. Además, el Estado se encuentra obligado a poner a disposición de la población recursos sencillos, urgentes, informales, accesibles y tramitados por órganos independientes, que permitan proteger dichos derechos de manera adecuada y efectiva ${ }^{16}$.

\footnotetext{
13 Aguilar (2013), pp. 120, 121, 128 y 129.

14 Comisión Interamericana de Derechos Humanos, Comunidades Indígenas Mayas del Distrito de Toledo con Belice (2004), párrafo 142; Grupo de Tratado Hul'quminnum con Canadá (2009), párrafos 50 y 51; Comunidad Agrícola Diaguita de los Huascoaltinos y sus miembros con Chile (2009), párrafos 57, 58, 60, 61 y 62; Comunidades Indigenas Ngöbe y sus miembros en el valle del río Changuinola con Panamá (2009), párrafo 46, y Miguel Ignacio Fredes González y Ana Andrea Tuczek Fries con Chile (2009), párrafos 54 y 55. Comisión Interamericana de Derechos Humanos (2011), párrafo 7, y (2011b), párrafo 6.

15 Corte Interamericana de Derechos Humanos, Pueblo Saramaka con Surinam (2007), párrafos 129 y 133.

16 Corte Interamericana de Derechos Humanos, Claude Reyes y otros con Chile (2006), párrafo 137.
} 
Incluso la CIDH se ha pronunciado acerca de otros derechos, como la libertad de expresión y la libertad de asociación los cuales, por verse vulnerados en razón de represiones, persecuciones o detenciones arbitrarias, constituirían, a su vez, un impedimento directo para la protección del medio ambiente ${ }^{17}$.

En relación al sistema europeo, el amplio ejercicio de los derechos humanos a la información, a la participación en los procesos de toma de decisiones y al acceso a la justicia, constituye un factor esencial para la protección ambiental. En este sentido, la jurisprudencia del TEDH ha considerado la protección procesal, que incluye el reconocimiento a una obligación firme de los gobiernos de proveer acceso a la información, participación de los ciudadanos y acceso a la justicia ${ }^{18}$. Así, por ejemplo, en los casos López Ostra con España y Guerra con Italia ${ }^{19}$, la ausencia de entrega de información por parte de los respectivos gobiernos sobre los riesgos ambientales constituyó para el TEDH una violación al artículo $8^{\circ}$ del CEDH.

De este modo, si bien en Europa los Estados poseen un considerable margen para determinar las medidas que estimen necesarias para asegurar los derechos relacionados con la protección del medio ambiente, las anomalías en el ejercicio de los derechos procedimentales, que terminan por afectar los derechos reconocidos por el CEDH, dan origen a responsabilidad internacional para el Estado infractor. De manera similar, en el caso Claude Reyes y otros con Chile, la Corte IDH resolvió que la falta de acceso a la información constituye una violación al artículo 13 de la $\mathrm{CADH}^{20}$.

En consecuencia, el Derecho Internacional exige a los Estados respetar y asegurar estos derechos humanos de carácter procedimental, de forma que la consagración y fortalecimiento de los mismos en el Derecho nacional es clave al momento de garantizar una adecuada cooperación de todos los sectores de la sociedad en los principales asuntos relacionados con la gestión y planificación sustentable de los recursos hídricos ${ }^{21}$.

17 Comisión Interamericana de Derechos Humanos, Comunidades Indigenas Ngöbe y sus miembros en el valle del río Changuinola con Panamá (2009), párrafos 46-48.

18 Bonine y KRavchenKo (2012), p. 27.

19 Tribunal Europeo de Derechos Humanos, Caso López Ostra con España (1994) y Guerra con Italia (1998).

20 Corte Interamericana de Derechos Humanos, Caso Claude Reyes y otros con Chile (2006).

21 En cuanto a la incidencia sobre el Derecho de Aguas de estos derechos procedimentales en materia ambiental, véase el apartado 2.1.2, de la segunda parte de este trabajo. 


\section{Una mirada desde el principio de igualdad y no discriminación: la degradación ambiental y los grupos vulnerables}

Un tercer planteamiento examina los efectos negativos que los daños ambientales significan para el cumplimiento de los derechos sustantivos de determinados grupos vulnerables o subordinados, y, por ende, la transgresión del principio de igualdad y no discriminación.

Así como hay derechos esencialmente individuales, que pueden ser protegidos únicamente en razón de una persona, existen otros derechos que, a su vez, pueden ser resguardados de manera colectiva, especialmente cuando es un grupo el afectado. De esta forma, existen grupos que son más aptos para una protección colectiva, y en razón de ello es que el Derecho Internacional contempla mecanismos de protección para ciertos grupos vulnerables como las mujeres, los niños, las personas en situación de discapacidad, las personas mayores, los pueblos indígenas y los trabajadores en determinadas condiciones ${ }^{22}$.

Así, por ejemplo, se ha puesto de manifiesto el estrecho vínculo entre las migraciones y el medio ambiente, proponiéndose dejar atrás la percepción de frustración adaptativa que tendría la migración a causa del cambio climático y adoptar una posición que perciba este fenómeno como una oportunidad para tratar correctamente la necesidad de los refugiados ambientales de adaptarse a las actuales condiciones de habitabilidad que el medio ambiente exige ${ }^{23}$. De esta manera, el disfrute de los derechos por parte de los grupos subordinados es una cuestión que puede verse obstaculizada por el cambio de las condiciones ambientales ${ }^{24}$. Igualmente, se sostiene que, muchas veces, ya sea por cuestiones socioeconómicas, de nacionalidad u origen racial, los servicios ambientales, por un lado, y los riesgos y daños al medio ambiente, por el otro, no se encuentran equitativamente distribuidos entre la población, lo que sería una materia propia de la justicia ambiental ${ }^{25}$.

\footnotetext{
22 CANÇADO (2013), pp. 267-276.

23 Campusano (2014), p. 251.

24 Campusano (2014), p. 276.

25 Bermúdez (2014), pp. 54 y 55. Concepto definido por Hervé como “... la distribución equitativa de las cargas y beneficios ambientales entre todas las personas de la sociedad, considerando en dicha distribución el reconocimiento de la situación comunitaria y de las capacidades de tales personas y su participación en la adopción de las decisiones que los afectan. Asimismo, la decisión que se adopte debe garantizar la integridad ecosistémica de la zona afectada”. Hervé (2013), p. 35.
} 
Para la CIDH “... la violación del derecho a la igualdad se produce al otorgar una protección ambiental desigual en base a la raza [u otra condición social], sin ninguna justificación razonable, creando una modalidad de racismo ambiental que no sirve ningún objetivo legítimo y estableciendo medios inadecuados e ineficaces para obtener la protección ambiental, en conocimiento de que las personas de color [u otros grupos vulnerables] soportan la carga desproporcionadamente sustancial de tales medidas inadecuadas e ineficaces" 26 .

De este modo, y en razón de diversos instrumentos internacionales ${ }^{27}$, la protección de los grupos vulnerables no se daría únicamente en el ámbito de los derechos humanos, ni en el del Derecho Ambiental Internacional, sino que en ambos campos jurídicos de manera conjunta ${ }^{28}$.

En virtud de lo anterior, los Estados se encuentran obligados a respetar y garantizar la protección del medio ambiente y los derechos humanos, pero además a asegurar que todos los mecanismos dispuestos en tal sentido se encuentren implementados sobre el principio de igualdad y no discriminación. Lo anterior implica que las legislaciones nacionales deben desarrollar todas las acciones encaminadas a acelerar la igualdad de facto de aquellas colectividades que han sido afectadas en el disfrute y ejercicio de sus derechos humanos a raíz de una inadecuada tutela ambiental, agudizando con ello una situación de discriminación prolongada en el tiempo.

Así, el desafío para las legislaciones estatales de aguas está en flexibilizar un sistema que permita adaptarse a las colectividades que históricamente, o en el último tiempo, se han visto perjudicadas en el acceso al agua, ya sea por la sobreexplotación o calidad de los recursos hídricos. Ello posibilitará la protección

26 Comisión Interamericana de Derechos Humanos, Mossville Environmental Action con Estados Unidos (2010), párrafo 42.

27 Cabe hacer presente el Convenio No 169 de la OIT, en el que se reconoce que la tierra tiene una importancia fundamental para la cultura y la vida de los pueblos indígenas, y que es la base de su subsistencia económica, bienestar espiritual e identidad cultural (artículos 13-19). Así como también la Declaración de Naciones Unidas sobre Derechos de los Pueblos Indígenas de 2007, que reconoce el derecho de estos pueblos "... a la conservación y protección del medio ambiente y de la capacidad productiva de sus tierras o territorios y recursos [...] sin discriminación” (artículo 29.1). Igualmente debe considerarse la Convención sobre los Derechos del Niño, la cual entiende que los riesgos y peligros ambientales constituyen una amenaza para el suministro de alimentos y agua potable, y por ende una amenaza al derecho a la salud (artículo 24, párrafo 2 b). Finalmente, el Protocolo de la Carta Africana de Derechos Humanos y de los Pueblos sobre los Derechos de la Mujer en África de 2003 reconoce el derecho de las mujeres a vivir en un entorno saludable y sustentable (artículo 18), y el goce pleno de su derecho al desarrollo sustentable (artículo 19).

28 CANÇADO (2013), p. 273. 
de grupos que exigen una atención preferente, como serían especialmente las personas que residen en zonas desérticas y en áreas rurales, las personas dedicadas a la pequeña agricultura, así como los miembros de pueblos originarios, pues todas estas colectividades se encuentran muy susceptibles a la escasez y mala calidad de las aguas. Todo lo anterior poniendo especial énfasis en las mujeres, los niños y niñas, las personas con discapacidad, las personas mayores, las personas migrantes, entre otras.

\section{El medio ambiente como limite a otros derechos humanos}

Es en razón del propio uso y goce de los elementos que componen el medio ambiente que se genera un vínculo con otros derechos humanos, donde el bien jurídico ambiental fija o puede fijar una restricción a distintos derechos y libertades fundamentales, como el derecho de propiedad, el de libertad de movimiento, el de libertad de emprendimiento o de desarrollo de actividades económicas.

Para la CIDH resulta indispensable que el desarrollo de las diversas actividades económicas se encuentre sujeto a determinadas medidas que permitan asegurar que dichas actividades no se realicen a costa del disfrute de los derechos humanos de las personas y su medio ambiente, del cual depende su bienestar físico, cultural e incluso espiritual ${ }^{29}$. En todo caso, para la Corte IDH, la declaración de un territorio como área silvestre protegida bajo dominio privado no puede desconocer el derecho de los miembros de comunidades indígenas sobre sus tierras tradicionales ${ }^{30}$.

En el sistema europeo, a través del artículo 8 del CEDH surge la obligación positiva por parte del Estado de adoptar medidas razonables y apropiadas que permitan garantizar los derechos de los demandantes. Así, el TEDH debe ponderar las ventajas colectivas frente a los intereses particulares de los individuos. En ambos casos, el Estado dispone de un cierto margen de apreciación al momento de decidir qué medidas deben adoptarse para garantizar el respeto del CEDH, y que eventualmente puede restringir el ejercicio de determinados derechos por parte de otros particulares ${ }^{31}$, que dicen relación especialmente con la explotación de recursos naturales y el desarrollo de actividades industriales o comerciales ${ }^{32}$.

29 Comisión Interamericana de Derechos Humanos, Comunidades Indígenas Mayas del Distrito de Toledo con Belice (2004), párrafo 150.

30 Corte Interamericana de Derechos Humanos, Xakmok Kásek con Paraguay (2010), párrafos 312 y 313.

31 Martínez (2013), pp. 4 y 5; Harrison (2013), p. 509; Martín-Retortillo, L. (2008), p. 790, y Simón (2010), p. 102.

32 Bonine y Kravchenko (2012), p. 38. 
La protección ambiental exige el respeto tanto de los particulares -al desarrollar diversas actividades económicas- como del Estado en su función de velar por que la realización de tales actividades se haga en cumplimiento de la normativa vigente ${ }^{33}$. En este sentido, se afirma que las denuncias por violación a los derechos humanos en materia ambiental buscan justamente responsabilizar al Estado por no haber regulado adecuadamente un asunto, o bien no haber exigido el cumplimiento de la ley, toda vez que la generalidad de los daños al medio ambiente proviene de actividades privadas ${ }^{34}$.

De esta manera, la tutela ambiental constituye un contrapeso al ejercicio irrestricto de aquellos derechos que permiten el desarrollo de múltiples actividades económicas e industriales y, por ende, la explotación de los recursos naturales. Lo anterior no significa que el derecho a un medio ambiente adecuado no pueda, a su vez, ser restringido por el ejercicio de estos derechos. Por el contrario, al no existir una jerarquía de derechos en el sistema internacional de derechos humanos, no hay derechos absolutos, por lo que la restricción deberá sujetarse a los estándares de proporcionalidad.

En consecuencia, el Derecho de Aguas en ningún caso debe estar configurado sobre la base de la libre explotación de los recursos hídricos por parte de los particulares, sino que, además, debe incorporar los mecanismos necesarios para garantizar un uso y gestión sustentable de las aguas que permita, asimismo, asegurar la protección del medio ambiente, y con ello el respeto y garantía de los derechos humanos que de él dependen. Lo anterior exige la incorporación de figuras que en cierta forma limiten el desarrollo de actividades económicas, como son la norma del uso efectivo y beneficioso; la regla que establece un orden de preferencia en razón de los distintos usos del agua; las disposiciones que reconocen y desarrollan el principio de unidad de cuenca hidrográfica, y las que establecen caudales ecológicos.

\section{El derecho autónomo a un medio ambiente adecuado}

En el ámbito universal, la existencia de un derecho autónomo a un medio ambiente adecuado aún no ha sido objeto de reconocimiento por parte de algún instrumento de carácter vinculante, lo que ha condicionado el estatus jurídico

33 GuZMÁN (2012), p. 43.

34 Shelton (2010), p. 115. 
de este derecho y ha generado una discrepancia doctrinaria acerca del contenido del mismo.

\subsection{Reconocimiento y estatus jurídico}

De conformidad al ya mencionado Informe de la Relatora Especial Fatma Zohra, desde la Declaración de Estocolmo en 1972 se ha ido elaborando una serie de instrumentos a nivel universal, regional y nacional que han desarrollado el fundamento jurídico del derecho al medio ambiente adecuado. Lo anterior, basado principalmente en la conexión entre la protección del medio ambiente, el desarrollo y el disfrute de los derechos humanos (párrafos 236-238), con lo cual se afirmaría el reconocimiento universal y regional del derecho humano a un medio ambiente adecuado (párrafo 240) ${ }^{35}$.

Así, por ejemplo, el Protocolo Adicional a la CADH en materia de Derechos Económicos, Sociales y Culturales (en adelante, Protocolo de San Salvador) reconoce expresamente que "[t]oda persona tiene derecho a vivir en un medio ambiente sano y a contar con servicios públicos básicos”, y que "[l] os Estados partes promoverán la protección, preservación y mejoramiento del medio ambiente" (artículo 11) ${ }^{36}$. Por su parte, desde 1972 hasta el año 2008, 119 Estados ${ }^{37}$ habían consagrado en sus respectivas constituciones algún tipo de garantía sobre este derecho, lo que daría cuenta de una emergente norma de Derecho Internacional consuetudinario.

No obstante, y sin perjuicio de aquel reconocimiento, se argumenta que las múltiples disposiciones constitucionales emplean términos muy disímiles entre sí, y en pocas ocasiones se consagran derechos independientes de otros bienes jurídicos ya tutelados por derechos humanos existentes, lo cual impediría definir con precisión el ámbito y el contenido de este derecho, dificultando con ello la

35 A dicho informe se anexó un Proyecto de Principios sobre los Derechos Humanos y el Medio Ambiente, en el cual se reconocía que "[ $\mathrm{t}$ ] odas las personas tienen derecho a un medio ambiente seguro, sano y ecológicamente racional. Este derecho y otros derechos humanos [...] son universales, interdependientes e indivisibles" (principio 2). Y se consagraban los derechos de información, de participación y de acceso a la justicia (principios 15, 18 y 20). Sin perjuicio de la trascendencia de estos documentos, la Comisión de Derechos Humanos no aprobó el informe ni el proyecto de principios, ni tampoco confirmó a la Relatora Especial.

36 No obstante, de acuerdo al artículo 19.6 del Protocolo de San Salvador, la violación de este derecho por parte del Estado no da lugar a la aplicación del sistema de peticiones individuales ante la CIDH y la Corte IDH.

37 Earth Justice (2008), pp. 90 y ss. 
uniformidad de la práctica estatal ${ }^{38}$. Asimismo, se afirma que la sola incorporación de estas disposiciones en las constituciones nacionales tampoco alcanza para demostrar una efectiva opinio juris. Pudiendo concluirse que tanto la normativa internacional como los reconocimientos constitucionales reafirman la existencia de los principios de los derechos humanos, más que establecer un nuevo derecho ${ }^{39}$. Ahora, si bien el derecho autónomo a un medio ambiente adecuado todavía no ha sido reconocido en el plano universal, no hay dudas de que ya ha ingresado al discurso jurídico de los derechos humanos, a lo menos con el estatus de soft law, encontrándose a la espera de ser cristalizado por el Derecho Internacional convencional o consuetudinario.

En nuestro ámbito nacional, la Constitución de 1980 reconoce explícitamente el derecho a vivir en un medio ambiente libre de contaminación ${ }^{40}$, el cual ha sido definido, tanto por la Corte Suprema como por el Tribunal Constitucional, como un derecho humano de jerarquía constitucional, con un carácter dual de derecho público subjetivo y colectivo a la vez ${ }^{41}$. Por consiguiente, y en virtud de la $\mathrm{CADH}$, la Corte IDH estaría obligada a decidir casos ambientales deducidos contra Chile, toda vez que no está permitido “... limitar el goce y ejercicio de cualquier derecho o libertad que pueda estar reconocido de acuerdo con las leyes de cualquiera de los Estados Partes o de acuerdo con otra convención en que sea parte uno de dichos Estados...” (artículo 29).

\subsection{Discusión doctrinaria sobre el carácter autónomo del bien jurídico medio ambiente}

Algunos autores conservadores entienden al medio ambiente no como un derecho humano autónomo, sino más bien en función de otros derechos humanos. Así, para Ferreira la protección ambiental es un elemento esencial para el disfrute de los derechos humanos, puesto que las condiciones ambientales determinan la extensión en la cual una sociedad disfruta de los derechos básicos. Agregando que el sistema de derechos humanos constituiría una estructura jurídica flexible, que exige la ampliación de sus normas frente a nuevas amenazas que pongan en riesgo

38 LEWIS (2012), pp. 42 y 43.

39 LEWIS (2012), p. 43.

40 Constitución Política de la República de Chile de 1980, artículo 19 No 8.

41 Corte Suprema, Rol No 2732-96, de 19 de marzo de 1997. Replicado en Sentencia Tribunal Constitucional, Rol No 1988-2011 CPT, de 24 de junio de 2011. 
la posibilidad real de los seres humanos de disfrutar de una vida digna, pero sin reconocer nuevos derechos ${ }^{42}$.

De manera similar, Simón descarta de plano la existencia de un derecho humano al medio ambiente como tal, afirmando que no se tutela el medio ambiente como bien colectivo, puesto que sería contradictorio con el carácter de derechos subjetivos que poseen los derechos humanos, sino que, por el contrario, se tutelan bienes jurídicos individuales en la medida en que son afectados por la degradación ambiental $^{43}$. De acuerdo a Carmona, este derecho adopta una visión amplia con el propósito de garantizar el derecho a la libertad, la igualdad y el goce de condiciones de vida óptimas en un entorno de calidad que permita llevar una vida digna, surgiendo además el deber de proteger y mejorar el ambiente tanto para las generaciones presentes como para las futuras ${ }^{44}$.

Otros autores, un tanto más progresistas, conciben al bien jurídico medio ambiente como un derecho humano independiente de los demás derechos fundamentales. Así, para Espinoza el derecho a un medio ambiente libre de contaminación se encuentra singularizado por su carácter colectivo y social ${ }^{45}$. En cambio, para Bruzón y Antúnez se trataría de un derecho colectivo, en razón de que se configuraría dentro de una etapa avanzada del proceso de evolución de los derechos humanos, los cuales se encuentran condicionados por el vertiginoso desarrollo de las últimas décadas ${ }^{46}$. Asimismo, Ríos afirma que este derecho tendría una dimensión dual, por una parte un carácter individual, debido a la legitimación particular de cada persona para exigir este derecho, y a su vez un carácter colectivo, en razón de la naturaleza física integral del medio ambiente como bien jurídico protegido, intensificado por la importancia de los derechos procedimentales ${ }^{47}$.

Una perspectiva, un tanto ecléctica, interpreta el vínculo como una protección ambiental necesaria para la realización y disfrute de los derechos y libertades individuales, es decir, como medio. Y, cuando lo anterior no resulta suficiente, debería

42 FERreira (2008), pp. 146-148.

43 Simón (2010), p. 91. En el mismo sentido, Fernández (2013), pp. 7-9.

44 Carmona (2010), p. 13.

45 EspinOza (2010), p. 176 y ss. Para el autor, ello se debería a que el Estado debe adoptar una serie de acciones para resguardar el cumplimiento del derecho, a diferencia de la marcada inactividad de los derechos civiles y políticos; así como también a la ausencia de una limitación legal del derecho a un medio ambiente adecuado, propio de aquellos derechos.

46 Bruzón y Antúnez (2012), p. 77.

47 Ríos (2014), pp. 62 y 73. 
reconocerse al medio ambiente sano y su protección como un fin en sí mismo y por ende como un derecho sustantivo ${ }^{48}$. Por su parte, Vernet y Jaria apuntan a que este derecho tiende a proyectarse en aspectos concretos de otros derechos, incidiendo de forma determinante en la configuración del catálogo general de derechos humanos reconocidos en los distintos niveles de protección a nivel internacional ${ }^{49}$.

En este orden de ideas, es posible sostener que el derecho a un ambiente adecuado presenta una dimensión individual y otra colectiva, con una preeminencia de su carácter cooperativo, que exige un empoderamiento de la ciudadanía por medio de los derechos procedimentales de acceso a la información, participación y acceso a la justicia, y un estricto cumplimiento del principio de igualdad y no discriminación. Ahora bien, en virtud del carácter global de su dimensión material, este derecho presenta cualidades adjetivas amplias, pues su amparo es fundamental para asegurar el cumplimiento de múltiples derechos humanos, siendo justamente la sobreexplotación y contaminación de los recursos hídricos la principal amenaza del derecho humano al agua y al saneamiento. Aspectos que serán analizados a continuación.

\section{El DERECHO HUMANO AL AGUA Y AL SANEAMIENTO Y LA GESTIÓN}

SUSTENTABLE DE LOS RECURSOS HÍDRICOS DESDE LA PERSPECTIVA INTERNACIONAL

Con el propósito de encontrar la pauta que el Derecho Internacional entrega a los Estados, para una configuración de sus legislaciones de aguas en consonancia con la protección de los derechos humanos y del medio ambiente, en esta segunda parte se abordan los aspectos más relevantes del reconocimiento internacional del derecho humano al agua y al saneamiento. Asimismo, se examinan los principios fundamentales que proporciona el Derecho Internacional para una gestión sustentable de los recursos hídricos, destinada a la protección del medio ambiente y a garantizar el derecho humano al agua y al saneamiento.

\section{El derecho humano al agua y al saneamiento}

La génesis del derecho humano al agua y al saneamiento se encuentra en una serie de conferencias internacionales celebradas en el contexto de las estrategias

48 Arístegui (2010), pp. 47 y 48.

49 Los autores afirman que esta figura se da especialmente en el caso del CEDH, particularmente a través de la incorporación de variables ambientales al contenido del derecho a la vida privada y familiar (artículo 8.1). VeRnet y JaRia (2007), p. 521. 
para el medio ambiente y el desarrollo. Así, en la Declaración de la Conferencia de Naciones Unidas sobre el Agua, suscrita en Mar del Plata en 1977, se reconoce como derecho de todos los pueblos el poder "... disponer de agua potable en cantidad y calidad suficiente para sus necesidades básicas".

Asimismo, la Declaración de la Conferencia Internacional sobre Agua y Medio Ambiente, adoptada en Dublín en 1992, confirma que “... es esencial reconocer ante todo el derecho fundamental de todo ser humano a tener acceso a un agua pura y al saneamiento por un precio asequible" (principio 4). Igualmente, en la Declaración de la Conferencia Internacional sobre el Agua Dulce, adoptada en Bonn en 2001, se entiende que para alcanzar un desarrollo sustentable se requiere la integración de los múltiples usos del recurso con los aspectos sociales, ambientales y económicos.

Por su parte, de la Conferencia de Naciones Unidas sobre el Medio Ambiente y el Desarrollo, celebrada en Río de Janeiro en 1992, derivaron una serie de instrumentos internacionales en materia ambiental, entre ellos el Programa 21, en el que se reconoce que el estrés hídrico y la progresiva contaminación de las aguas requieren una planificación y una gestión integrada de los recursos hídricos (párrafo 18.3).

De esta manera, estos instrumentos internacionales ponen un énfasis particular en el nexo existente entre el desarrollo, la conservación de las aguas y el medio ambiente, en donde la protección ambiental es considerada como el presupuesto imprescindible para garantizar la disponibilidad del recurso para el consumo humano.

\subsection{Reconocimiento y estatus jurídico}

El Derecho Internacional convencional no consagra expresamente el derecho al agua y al saneamiento como un derecho autónomo. No obstante, diversos tratados internacionales en la materia disponen obligaciones específicas respecto a este derecho ${ }^{50}$.

El sistema interamericano, si bien no contempla expresamente el derecho al agua, sus órganos han construido una protección de este derecho como respuesta

50 Véanse Convención sobre la Eliminación de todas las Formas de Discriminación contra la Mujer de 1979 (artículo 14.2 letra g), Convención sobre los Derechos del Niños de 1989 (artículo 24.2 letra c), Convenio No 169 de la Organización Internacional del Trabajo, sobre Pueblos Indígenas y Tribales en Países Independientes de 1989 (artículo 15), la Declaración de Naciones Unidas sobre los Derechos de los Pueblos Indígenas de 2007 (artículo 25), la Convención Internacional sobre los Derechos de las Personas con Discapacidad de 2006 (artículo 28.2 letra a) y la reciente Convención Interamericana sobre la Protección de los Derechos Humanos de las Personas Mayores de 2015 (artículo 25 letra b). 
a la violación de determinados derechos civiles y políticos que son ampliamente protegidos por este sistema regional, como el derecho a la vida, la propiedad, la integridad física y la igualdad de oportunidades y la no discriminación ${ }^{51}$.

En el ámbito universal, el Pacto Internacional sobre Derechos Económicos, Sociales y Culturales de 1966 (en adelante, Pidesc) tampoco hace referencia explícita a este derecho; sin embargo, el Comité de Derechos Económicos, Sociales y Culturales; en adelante, Comité DESC a través de su Observación General No 15 de 2002, hace una interpretación amplia de los artículos 11.1 y 12.1 de dicho tratado. Así, entiende que el derecho humano al agua y al saneamiento se encuentra reconocido de manera implícita en el derecho a un nivel de vida adecuado “... incluso alimentación, vestido y vivienda...", y vinculado con el derecho a la vida y la dignidad humana, y al más alto nivel de salud (párrafos 1 y 3).

A su vez, la Asamblea General de Naciones Unidas, en su Resolución No 64/292 de 2010, sobre el derecho humano al agua y al saneamiento, reconoce claramente que se trata de un derecho humano esencial para el pleno disfrute de la vida y de todos los derechos humanos ${ }^{52}$.

En concreto, en el ámbito universal el derecho al agua y al saneamiento, al igual que el derecho a un medio ambiente adecuado, no ha sido abordado como un derecho autónomo de manera expresa por ningún instrumento convencional. $\mathrm{Ni}$ tampoco reuniría los requisitos de uniformidad y opinio juris propios de la costumbre internacional. En efecto, su estatus jurídico no sería de una norma jurídica vinculante, sino más bien de soft law ${ }^{53}$, formando parte de los denominados derechos humanos emergentes, en el sentido que aspiran a ser solidificados definitivamente por el Derecho Internacional.

\subsection{Contenido normativo}

La Observación General No 15, de 2002, define el derecho humano al agua como "... el derecho de todos a disponer de agua suficiente, salubre, aceptable, accesible y asequible para el uso personal y doméstico" (párrafo 2).

Así, los elementos normativos del contenido mínimo de este derecho, son: a) la disponibilidad, esto es la continuidad y suficiencia del abastecimiento de agua

51 SALMÓN (2012), p. 251.

52 Asamblea General de Naciones Unidas, Resolución No 64 /292, El derecho humano al agua y el saneamiento, doc. A/L.63/Rev. $1^{\circ}$, de 28 de julio de 2010, párrafo 1.

53 En este sentido, Kirschner (2011), p. 465. 
para usos personales y domésticos; b) la calidad, que se refiere a la salubridad del agua, libre de degradación y contaminación que pueda constituir un peligro para la salud, y c) la accesibilidad, es decir, que el agua, las instalaciones y servicios de abastecimiento deben ser accesibles física y económicamente para todas las personas en igualdad de oportunidades y sin discriminación, debiéndose incluso entregar la información necesaria que garantice una adecuada participación de la sociedad civil (párrafos 12 y 17).

En cuanto al saneamiento, la Observación General No 15 se limita a reconocer los servicios sanitarios como el mecanismo imprescindible para la protección de la calidad del agua potable y sus reservas, y con ello garantizar el disfrute del derecho a la salud y el derecho a una vivienda adecuada, particularmente en zonas rurales y urbanas vulnerables (párrafo 29). El Comité DESC sostiene que el saneamiento es “... un sistema para la recogida, el transporte, el tratamiento y la eliminación o reutilización de excrementos humanos y la correspondiente promoción de la higiene”. Para lo cual los Estados “... deben garantizar, sin discriminación, que toda persona tenga acceso, desde el punto de vista físico y económico, al saneamiento, en todas las esferas de la vida, que sea inocuo, higiénico, seguro, aceptable, desde el punto de vista social y cultural, proporcione intimidad y garantice la dignidad" 54 .

De acuerdo a lo anterior, es posible entender que el derecho humano al agua se estructura desde una dimensión objetiva como un derecho prestacional, fundado en los principios de Derecho Público de igualdad, continuidad, regularidad, generalidad y obligatoriedad del servicio. Mientras que desde un punto de vista amplio, se configura como un derecho público subjetivo, basado en normas imperativas de carácter intersectorial y medioambiental ${ }^{55}$.

En consecuencia, el derecho humano al agua y al saneamiento se encuentra configurado a través de una serie de dimensiones. La primera de ellas, de carácter objetivo, dice relación con el suministro regular del recurso, que incluye los servicios de producción y distribución de agua potable, así como también la construcción de las obras e infraestructura necesaria para su captación, transporte y consumo, de manera accesible, física y económicamente, para toda la población.

Una segunda dimensión, de carácter subjetiva, está compuesta por la finalidad del derecho que se traduce en el uso de las aguas para consumo humano. De esta manera, el objetivo señalado limita en principio el ejercicio del derecho al

54 Comité de Derechos Económicos Sociales y Culturales (2010), párrafo 8.

55 Mitre (2012), p. 412. 
uso personal y doméstico suficiente, para garantizar el disfrute de otros derechos humanos, tales como la alimentación y la salud, proyectándose de esta forma como un derecho de mínimos.

Por su parte, una tercera fase está constituida por el sustrato material de este derecho humano: las aguas. Es respecto de los recursos hídricos que se exigen estándares de calidad y suficiencia mínima como para asegurar el consumo humano. De manera que el saneamiento y la gestión sustentable de las aguas se requieren como resultado de la dimensión física de este derecho.

Por último, una cuarta fase hace referencia al aspecto transversal del derecho al agua, constituido por su carácter igualitario y no discriminatorio, como imperativo intrínseco a todo derecho humano. Es en virtud de este rasgo que las dimensiones objetiva, subjetiva y la protección del sustrato material deben proyectarse y concretarse con especial consideración de los diversos grupos vulnerables.

\subsection{Obligaciones internacionales derivadas del derecho humano al agua y al saneamiento}

De acuerdo al Pidesc y a la Observación General No 15, los Estados deben cumplir con una serie de obligaciones generales y particulares de preeminente carácter progresivo. No obstante, en primer lugar, cabe destacar el deber inmediato, y por ende no afecto a progresividad, de garantizar el ejercicio del derecho humano al agua y al saneamiento en condiciones de igualdad y no discriminación (párrafos 13 a 16, 37 letra f y 48).

A su vez, los Estados tienen la obligación de adoptar todas las medidas que les permitan avanzar de la manera lo más rápida y efectiva posible, y hasta el máximo de sus recursos disponibles, para alcanzar el disfrute pleno de este derecho (párrafos 18 y 41), incluidas las medidas legislativas (artículo 2.1, Pidesc). Estableciéndose la presunción de que las medidas regresivas se encuentran prohibidas por el Pidesc (párrafos 19 y 42).

Además, el Estado tiene el deber de garantizar el derecho de todas las personas a solicitar, recibir y difundir información sobre temas relativos al agua y al medio ambiente, y adoptar una estrategia y un plan de acción nacional elaborado bajo un procedimiento participativo y transparente (párrafos 12, 37 y 48), así como también la obligación de garantizar los recursos judiciales que permitan a las víctimas de violaciones del derecho humano al agua obtener una reparación adecuada (párrafo 55).

En segundo lugar, los Estados deben cumplir con ciertas obligaciones específicas, partiendo por la obligación de respetar, esto es, el deber de abstenerse de 
realizar cualquier práctica que de modo directo o indirecto interfiera en el disfrute y ejercicio del derecho humano al agua, como sería la existencia de cortes arbitrarios, el aumento desproporcionado del precio del agua y la contaminación del agua (párrafo 21 y 44 letra a).

Igualmente, los Estados tienen la obligación de proteger, es decir, de impedir que terceros obstaculicen o interfieran en el disfrute y ejercicio de este derecho, como sería el impedimento al acceso igualitario y sin discriminación, la contaminación o explotación de los recursos hídricos de manera no equitativa. Para lo cual el Estado debe adoptar todas las medidas necesarias para asegurar este derecho, incluidas las adecuaciones normativas (párrafo 23) 56 .

Por su parte, la obligación de cumplir se divide a su vez en: a) la obligación de facilitar, según la cual los Estados deben adoptar las medidas necesarias que permitan a toda persona ejercer este derecho; b) la obligación de promover, en razón de la cual el Estado debe difundir la información sobre el uso, protección y métodos de eficiencia del recurso, y c) la obligación de garantizar, en virtud de la cual los Estados deben adoptar las acciones afirmativas que permitan a todas las personas y grupos subordinados el pleno disfrute y ejercicio del derecho humano al agua (párrafo 25).

Así, el Estado, por una parte, debe abstenerse de adoptar cualquier decisión que obstaculice el ejercicio de este derecho y, por otra, requiere fijar límites a las diversas actividades privadas que puedan entorpecer el disfrute del mismo ${ }^{57}$. Igualmente, los Estados se ven obligados a adoptar las acciones positivas que les permitan eliminar la desigualdad de facto que pueda impedir a las personas en situación de vulnerabilidad ejercer adecuadamente el derecho al agua. Todo ello garantizado por los derechos procedimentales que aseguren a la sociedad civil un adecuado acceso a la información, una real participación en la toma de decisiones y las acciones judiciales idóneas para resarcir los eventuales daños causados.

\subsection{La dimensión ambiental del derecho humano al agua y al saneamiento}

La protección del medio ambiente es imprescindible para el disfrute del derecho humano al agua y al saneamiento, puesto que de ella depende al menos la

\footnotetext{
56 En el caso en que los servicios de abastecimiento hayan sido entregados a privados, el Estado debe regular un sistema que permita la fiscalización y el establecimiento de sanciones, contemplando una "auténtica participación pública”, (párrafo 24).

57 SAURA (2012), pp. 177 y 178.
} 
disponibilidad y la calidad del recurso. De este modo, para garantizar el ejercicio de este derecho se requiere tanto la adopción de medidas políticas como jurídicas, integradas con una gestión sustentable de los recursos hídricos ${ }^{58}$. Además, se debe tener en cuenta que la vulneración del derecho humano al agua y al saneamiento dificulta el desarrollo sustentable y la justicia ambiental ${ }^{59}$.

De igual forma, el Comité DESC entiende que el ejercicio del derecho humano al agua "... debe ser sostenible de manera que este derecho pueda ser ejercido por las generaciones actuales y futuras" 60 . Con este mismo objetivo, se establece la obligación de los Estados de adoptar estrategias y programas para evitar la sobreexplotación y la contaminación de los recursos hídricos, considerando factores como el cambio climático, la desertificación y deforestación, así como la pérdida de biodiversidad ${ }^{61}$.

No obstante, el derecho humano al agua y al saneamiento, al ser esencialmente antropocéntrico y conceptualmente limitado a un mínimo -cantidad mínima para el uso personal y doméstico-, su protección sólo puede proyectarse a los recursos hídricos necesarios para satisfacer las necesidades básicas de la población. Por consiguiente, la gestión y preservación de las aguas debe ser asumida necesariamente por el Derecho (Internacional) Ambiental y el Derecho (Internacional) de Aguas ${ }^{62}$. De esta manera, y considerando que las principales dificultades del acceso al agua dicen relación con su estado y conservación, es que la garantía de este derecho se encuentra estrechamente vinculada con la protección -o degradación- del medio ambiente y el crecimiento económico, más que con aspectos propios de los derechos humanos. Lo anterior ha llevado a proponer la construcción de un solo derecho que incluya como elementos constitutivos al agua y al saneamiento de forma conjunta con la protección ambiental63.

En consecuencia, y en razón de la interdependencia, interrelación e indivisibilidad de los derechos humanos, y de la importancia del agua como componente

58 LASKOWSKI (2012), pp. 167 y 168.

59 LASKOWSKI (2012), p. 165.

60 Comité de Derechos Económicos, Sociales y Culturales (2003), párrafo 11.

61 Comité de Derechos Económicos, Sociales y Culturales (2003), párrafo 28. De este modo, se considera una violación a la obligación de respeto la contaminación del agua que genere peligro para la salud de la persona humana, así como también la ausencia o incumplimiento de la normativa necesaria para evitar la contaminación o explotación desigual del recurso, (párrafo 44).

62 RÜEgGer (2014), pp. 17 y 18.

63 Serrano (2014), p. 296. 
de la fase física de estos derechos, es que el Derecho Internacional exige que los Derechos nacionales implementen la normativa internacional de manera integral y no parcializada. Para ello, es clave el rol del Derecho de Aguas como rama sectorial, en el sentido de fusionar la regulación del contenido del derecho al agua y el saneamiento con la protección y conservación del medio ambiente.

\section{Los principios fundamentales del Derecho Internacional referentes a una gestión sustentable de los recursos hidricos}

Las obligaciones convencionales asumidas por los Estados en el Derecho Internacional de los Derechos Humanos (en adelante, DIDH) coinciden con aquellos compromisos adoptados en los tratados internacionales sobre medio ambiente, puesto que en ambos casos el objetivo final $-\mathrm{o}$ al menos uno de sus objetivos finales- está constituido por la necesidad de garantizar el bienestar de la persona humana ${ }^{64}$.

De esta manera, es pertinente estudiar tanto los principios fundamentales del Derecho Internacional del Medio Ambiente (en adelante, DIMA) como los principios particulares del Derecho Internacional de Aguas (en adelante, DIA). Lo anterior con la finalidad de incorporar en la legislación nacional los mecanismos necesarios para una gestión sustentable de los recursos hídricos, que permitan una adecuada protección del medio ambiente y una garantía de los demás derechos humanos relacionados, con estricto cumplimiento del principio de igualdad y no discriminación.

\subsection{Principios generales}

En este apartado se abordan los principios fundamentales del DIMA y su proyección en el DIA.

\subsubsection{Los principios de prevención y precaución}

Resulta imprescindible para los Estados armonizar el desarrollo de las actividades económicas con la conservación del medio ambiente como garantía para

64 Ello se refleja en la similitud que presentan en el DIDH y el Derecho Internacional del Medio Ambiente los mecanismos de aplicación, monitoreo y evaluación de las obligaciones contraídas en el ámbito internacional, así como también la preferencia por utilizar similares figuras procedimentales de protección de los derechos en el plano nacional. Fuentes y Arístegui (2014), pp. 68 y 69. 
la supervivencia y bienestar de todas las personas, permitiendo a las autoridades adoptar decisiones que posibiliten alcanzar un punto de equilibrio entre ambos intereses ${ }^{65}$.

Desde la perspectiva del DIMA, la Declaración de Río consagra los principios de prevención y precaución que pretenden evitar daños ambientales. De acuerdo al principio de prevención, los Estados tienen la obligación de velar por que las actividades que se realicen dentro de su jurisdicción o bajo su control no causen daños al medio ambiente de otros Estados o de zonas más allá de su jurisdicción (principio 2) ${ }^{66}$. A su vez, dicho instrumento internacional establece que, con el propósito de una adecuada protección del medio ambiente, los Estados deben sujetarse al principio de precaución, en virtud del cual, la ausencia de certeza científica no puede utilizarse como excusa para no adoptar las medidas necesarias que permitan evitar el deterioro ambiental (principio 15) ${ }^{67}$. La Convención Marco de las Naciones Unidas sobre Cambio Climático, de 1992, dispone que los Estados partes “... deberían tomar medidas de precaución para prever, prevenir o reducir al mínimo las causas del cambio climático y mitigar sus efectos adversos. Cuando haya amenaza de daño grave o irreversible, no debería utilizarse la falta de total certidumbre científica como razón para posponer tales medidas..." (artículo 3.3).

Así, la regulación de los riesgos inciertos es la pieza fundamental del principio de precaución, donde la relación de causalidad entre una determinada actividad y el riesgo que ella produce se ignora ${ }^{68}$, a diferencia del deber de prevención, donde los riesgos originados por una actividad son previamente conocidos. Por ende, los poderes públicos deben gestionar tanto las amenazas ciertas - prevención- como las inciertas - precaución-, considerando no sólo las actividades que seguramente causarán daños, sino también aquellas que eventualmente podrían llegar a causarlo ${ }^{69}$, es decir, donde existe una incertidumbre cientifica. En este sentido, el TEDH ha señalado expresamente que el principio de precaución recomienda a los Estados no tardarse en la adopción de medidas preventivas, sencillamente

65 JARIA (2011), pp. 246.

66 Esta disposición replica el artículo 21 de la Declaración de la Conferencia de Naciones Unidas sobre Medio Ambiente Humano (1972).

67 Para Zander, si bien este principio ha emergido rápidamente en el DIMA, no constituiría una norma de derecho internacional propiamente tal, sino más bien un objetivo de policía que fijaría un estándar en la materia. ZANDER (2010), pp. 72 y 73.

68 ZANDER (2010), p. 31.

69 Cerski (2011), p. 86. 
por la existencia de una incertidumbre científica, debiendo gestionar los riesgos sobre el medio ambiente y la salud de la población ${ }^{70}$. Lo anterior implica una revisión de la influencia que ejerce el manifiesto científico en los gobiernos, y que termina por privar a la ciencia de su carácter de garante inequívoco de la verdad de las decisiones públicas ${ }^{71}$.

De esta forma, el principio de precaución conforma la materialización jurídica del juicio sobre el riesgo, de tal manera que las decisiones protectoras del medio ambiente queden limitadas por el derecho ${ }^{72}$, al igual que todas aquellas actividades económicas que puedan atentar contra la preservación del entorno. Por consiguiente, nace la necesidad de configurar los diversos instrumentos jurídicos dirigidos a prevenir efectivamente el surgimiento de nuevos riesgos para la sociedad y el medio ambiente $^{73}$. En este sentido, el acceso a la información, por parte de la sociedad civil, referente al análisis y a la responsabilidad del riesgo social, es crucial al momento de legitimar las estrategias de regulación que hayan sido adoptadas ${ }^{74}$.

Por su parte, la Convención de Naciones Unidas sobre el Derecho de los Usos de los Cursos de Agua Internacionales para fines distintos de la navegación, adoptada en $1997^{75}$ (en adelante, Convención sobre Cursos de Agua Internacionales), consagra la obligación de los Estados de utilizar los cursos de agua internacional, adoptando todas las medidas apropiadas para impedir que se causen daños sensibles a dicho curso de agua en el territorio de otros Estados (artículo 7.1), haciendo referencia a la protección y preservación de los ecosistemas y a la prevención, reducción y control de la contaminación (artículos 20 y 21). De este modo, esta obligación debe interpretarse desde la óptica del principio de precaución, de manera que permita gestionar adecuadamente los recursos hídricos frente a una incertidumbre científica respecto a si determinada actividad puede o no producir un daño sensible a las aguas.

Así, en cumplimiento de los principios de prevención y precaución, el Derecho de Aguas doméstico debe entregar los mecanismos jurídicos que permitan a la

70 Tribunal Europeo de Derechos Humanos, Tatar con Rumanía (2009), párrafos 107 y 109.

71 EмBid (2010), p. 117.

72 JARIA (2011), p. 247.

73 EMBid (2010), p. 117.

74 ZANDER (2010), p. 32.

75 Esta convención entró en vigencia el 17 de agosto de 2014. Y sin perjuicio de que Chile no la haya suscrito ni aún se haya adherido a ella, este tratado viene a codificar normas de Derecho Internacional consuetudinario ya consagradas en una serie de declaraciones internacionales. LlANOS (2007), pp. 251 y 252. 
Administración actuar de forma preventiva y precautoria, y no únicamente cuando exista un riesgo de daño inminente para los recursos hídricos. De este modo, el organismo público podrá contar con las herramientas necesarias para planificar y gestionar de manera sustentable las aguas en consonancia con los objetivos ambientales. Asimismo, la legislación de aguas debe facultar a la administración para condicionar los derechos de aprovechamiento de aguas a un uso efectivo y beneficioso de estos recursos, entregándole la posibilidad de hacer caducar dichos derechos en caso de incumplimiento.

\subsubsection{Acceso a la información, participación y acceso a la justicia en materia de medio ambiente: el principio de cooperación}

En el ámbito universal, el principio de cooperación o colaboración en materia de medio ambiente se encuentra ampliamente reconocido en los principios 7, 9, 10 y 14 de la Declaración de Río. Así, los principios 7 y 14 hacen alusión a la cooperación internacional entre Estados ${ }^{76}$, mientras que el principio 9 se refiere a la necesidad de la cooperación estatal dentro del propio Estado. Por su parte, el principio 10 aborda la colaboración de la sociedad civil, disponiendo que "[e]l mejor modo de tratar las cuestiones ambientales es con la participación de todos los ciudadanos interesados, en el nivel que corresponda"77.

A su vez, la Convención de Naciones Unidas para la Lucha contra la Desertificación dispone que la cooperación es un principio de la protección y conservación de la tierra y los recursos hídricos, que debe estar inserto en todos los niveles (gobierno, sociedad civil y usuarios) con la finalidad de entender de mejor manera las características y el valor de la tierra y las aguas, así como la promoción sustentable de dichos recursos (artículos 3 letra c y 4.2 letra c).

Asimismo, la Convención sobre Cursos de Agua Internacionales dispone que los Estados tienen el derecho a participar de forma equitativa y razonable en el uso de un curso de agua internacional y, a su vez, la obligación de cooperar en su aprovechamiento y protección con la finalidad de alcanzar un uso óptimo y sustentable y una protección adecuada del curso de agua respectivo (artículos 5 y 8). De esta manera, se establece la obligación de los estados de entregarse mutua-

76 En igual sentido, artículo 24 de Declaración de la Conferencia de Naciones Unidas sobre Medio Ambiente Humano (1972).

77 Para ello el principio 10 pone énfasis en el acceso a la información y recursos pertinentes para el resarcimiento de daños. 
mente, y de manera regular, la información disponible sobre el estado y calidad del curso de agua, así como las medidas previsoras correspondientes (artículos 9 y 31). Es más, esta convención dispone que para hacer efectiva la utilización y participación equitativas y razonables, y cuando sea necesario, los Estados deben celebrar consultas con un espíritu de cooperación (artículo 6). Igualmente, se establece el deber de los Estados de garantizar sin discriminación el acceso a la justicia de personas naturales o jurídicas, para solicitar la indemnización o reparación de los daños transfronterizos sensibles como consecuencia de actividades relacionadas con el curso de agua internacional respectivo (artículo 32)78.

En Europa, por su parte ${ }^{79}$, tiene gran importancia el Convenio de Aarhus sobre Acceso a la Información, la Participación del Público en la Toma de Decisiones y el Acceso a la Justicia en Materia de Medio Ambiente de $1998^{80}$, que reconoce los derechos descritos anteriormente con la finalidad de proteger el derecho de toda persona, y de las generaciones presentes y futuras, a vivir en un medio ambiente que garantice el disfrute y ejercicio de su derecho a la salud y su bienestar (artículo 1) ${ }^{81}$.

Así, partiendo de la base, que las decisiones referentes al aprovechamiento de los recursos naturales guardan relación con un riesgo social, es razonable estimar que sea la propia sociedad en su conjunto quien determine los riesgos que está dispuesta a asumir. Por consiguiente, cada Estado tiene la obligación internacional de implementar y asegurar todos los mecanismos que resulten necesarios para una adecuada colaboración de la sociedad civil en los asuntos hídricos, para lo cual la legislación de aguas deberá integrar y fortalecer los derechos de acceso a la información, participación y acceso a la justicia.

En consecuencia, la legislación nacional de aguas debe establecer los mecanismos que aseguren a la ciudadanía tener acceso a los principales datos relacionados con la disponibilidad y calidad de los recursos hídricos, con el otorgamiento de las concesiones o derechos de aguas y los diversos usos que los privados le dan a los mismos, así como toda aquella información indispensables para el diseño de la políticas públicas en la materia. De esta manera, el diseño de la planificación

\footnotetext{
78 Cerski (2011), p. 94.

79 En el caso del sistema interamericano, véase el apartado 2 de la primera sección de este trabajo.

80 Comisión Económica para Europa, Convenio sobre Acceso a la Información, la Participación del Público en la Toma de Decisiones y el Acceso a la Justicia en Materia de Medio Ambiente (1998).

81 Las normas de este tratado son plenamente aplicables para el ejercicio del derecho humano al agua y al saneamiento. Comisión de Derecho Internacional (2004), párrafo 32.
} 
y gestión de los recursos hídricos debe contar con la participación de todos los actores sociales (administración, sociedad civil y usuarios), que posibilite una efectiva cooperación en la protección de los recursos hídricos y en el resguardo del derecho humano al agua.

En lo referente al acceso a la justicia, el Derecho doméstico, junto a establecer una acción judicial, a nivel constitucional o legal, que consagre una acción rápida, flexible y sencilla para garantizar el pleno goce y ejercicio del derecho humano al agua y al saneamiento, debe fortalecer los mecanismos procedimentales que permitan asegurar los derechos de acceso a la información y participación en la toma de decisiones.

\subsubsection{Más allá de 'quien contamina, paga': el principio de responsabilidad}

De acuerdo al principio 16 de la Declaración de Río, "[l]as autoridades nacionales deberían procurar fomentar la internalización de los costos ambientales y el uso de instrumentos económicos, teniendo en cuenta el criterio de que el que contamina debe, en principio, cargar con los costos de contaminación, teniendo debidamente en cuenta el interés público y sin distorsionar el comercio ni las versiones internacionales". Asimismo, el principio 13 consagra que "[1]os Estados deberán desarrollar la legislación nacional relativa a la responsabilidad y la indemnización respecto de las víctimas de la contaminación y otros daños ambientales".

De este modo, este principio es más amplio que el simple hecho de que 'quien contamina, paga', pues comprende no sólo los costos derivados de la contaminación propiamente tal, sino también aquellos originados por la degradación del entorno, incluidos los provenientes de la (sobre)explotación de los recursos naturales.

Así, de acuerdo a la Declaración de la Conferencia de Naciones Unidas sobre Medio Ambiente Humano y "[d]e conformidad con la Carta de las Naciones Unidas y los principios del derecho internacional, los Estados tienen el derecho soberano a explotar sus propios recursos en aplicación de su propia política ambiental, y la obligación de asegurar que las actividades que se lleven a cabo dentro de su jurisdicción o bajo su control no perjudiquen al medio de otros Estados o de zonas situadas fuera de toda jurisdicción nacional" (principio 21). En consecuencia, "[1] os Estados deben cooperar para continuar desarrollando el derecho internacional en lo que se refiere a la responsabilidad y a la indemnización a las víctimas de la contaminación y otros daños ambientales que las actividades realizadas dentro de la jurisdicción o bajo el control de tales Estados causen a zonas situadas fuera de su jurisdicción" (principio 22). 
Por su parte, en virtud de la Convención sobre Cursos de Agua Internacionales, cuando un Estado, al utilizar un curso de agua, cause daño sensible a otro, deberá, en consulta con el Estado afectado, adoptar todas las medidas necesarias “... para eliminar o mitigar esos daños y, cuando proceda, examinar la cuestión de la indemnización” (artículo 7.2).

Es así como surge el principio de responsabilidad, en virtud del cual la concertación de los riesgos aceptados y rechazados permite a la sociedad definir las responsabilidades que deben corresponder a cada uno de sus actores por los efectos negativos que podrían llegar a originarse en razón del ejercicio de determinadas actividades económicas ${ }^{82}$. De esta manera, el ámbito privado deja de poseer una libertad incondicionada, en donde se explotan los recursos naturales sin asumir ningún coste por el deterioro ambiental, para dar paso a una libertad responsable en donde los particulares deben internalizar los costes por dichos daños, comprometiéndose de esta manera en la consecución de los propósitos ambientales ${ }^{83}$. A través de este principio se deben internalizar no sólo los costes derivados de la reparación de los daños, sino que también aquellos necesarios para prevenirlos. Además, una actuación diligente de los poderes públicos exige una responsabilidad del propio Estado, de manera que si, cumpliéndose todas las normas y parámetros admitidos para el ejercicio de las actividades económicas, igualmente se causa un perjuicio al entorno, el Estado debe responder ${ }^{84}$.

En síntesis, la legislación nacional de aguas debe articularse desde la base del principio de responsabilidad, de modo tal que tanto el aprovechamiento y gestión de los recursos hídricos como los daños causados por su sobreexplotación y contaminación, incluida la reparación a las víctimas, deben ser de cargo de los titulares de los proyectos económicos y, en último lugar, del Estado. En caso contrario, el Estado estaría incumpliendo con su obligación de garantizar el pleno goce y ejercicio de los derechos. En este orden de ideas, el Derecho de Aguas debe facultar a la administración para limitar el tiempo por el que se otorguen las concesiones o derechos sobre el recurso, de forma que se posibilite una revisión posterior de las condiciones y los usos prioritarios frente a factores externos. Así como también, para exigir el pago de cánones y tributos de conformidad a los distintos usos que se le den a las aguas, ya sea doméstico, agrícola, industrial, hidroeléctrico,

82 Cerski (2011), p. 98.

83 JARIA (2011), pp. 295 y 296.

84 Cerski (2011), pp. 98 y ss. 
entre otros; pago que, en todo caso, la administración deberá eximir cuando sea necesario para garantizar el acceso igualitario al derecho al agua y al saneamiento a una determinada colectividad.

\subsection{Principios especificos}

En este último apartado se abordan los principios particulares del DIA que permiten garantizar tanto el derecho humano a un medio ambiente adecuado como el derecho humano al agua y al saneamiento.

\subsubsection{La gestión integrada de las aguas: el principio de unidad de cuenca hidrográfica}

El eje central de la planificación de los recursos hídricos debe estar constituido por el principio de unidad de cuenca hidrográfica. La noción de cuenca hidrográfica es empleada por la geografía para referirse al ámbito territorial cuyo conjunto de aguas afluyen a un mismo río, lago o mar. Así, la escorrentía de aguas superficiales hacia el mar se efectúa por medio de las cuencas de los principales ríos o desde terrenos vertientes con aguas intermitentes ${ }^{85}$. Este concepto está dirigido a asegurar un uso integrado y completo de los recursos hídricos, así como a proteger la calidad de las aguas y de los ecosistemas vinculados a la propia cuenca. Por ello se sostiene que su gestión debe realizarse de manera unitaria y global, no debiendo fragmentarse en razón de tramos que atiendan a cursos fluviales considerados aisladamente ${ }^{86}$.

En el ámbito de la Unión Europea, la Directiva 60/2000/CE, por la que se establece un marco comunitario de actuación en el ámbito de la política de aguas, define a la cuenca hidrográfica como “... la superficie de terreno cuya escorrentía superficial fluye en su totalidad a través de una serie de corrientes, ríos y, eventualmente, lagos hacia el mar por una única desembocadura, estuario o delta" (artículo 2.13).

En el plano universal, la Convención sobre Cursos de Agua Internacionales emplea el término curso de agua para hacer alusión al "... sistema de aguas de superficie y subterráneas que, en virtud de su relación física, constituyen un conjunto unitario y normalmente fluyen a una desembocadura común” (artículo 2 letra a).

85 Fanlo (2007), p. 77.

86 FANLO (2007), pp. 77 y 78. 
De este modo, la noción de curso de agua internacional se extiende tanto a los Estados en cuyo territorio fluyen aguas superficiales como a aquellos en donde corren aguas subterráneas que desembocan en un río de otro Estado, afectando incluso a los particulares titulares de derechos de aprovechamiento con obligaciones de preservación de la cuenca fluvial ${ }^{87}$. Ahora, si bien el término cursos de agua internacional difiere del de cuenca hidrográfica, en la práctica esta diferencia es meramente formal, toda vez que el concepto de cursos de agua se compone de los mismos elementos fundamentales que configuran al de cuenca hidrográfica, como son la interdependencia material, la unidad geográfica y económica, y la obligación de un uso sustentable e integrado ${ }^{88}$.

Así, tratándose de las cuencas compartidas, la gestión integrada constituye la piedra angular de una estrategia internacional destinada a optimizar la distribución de las aguas, garantizando con ello un adecuado desarrollo social y económico, dejando atrás el mero reparto ${ }^{89}$. Asimismo, se entiende que este principio requiere la adopción de planes hidrológicos conjuntos, así como también la relativización de la soberanía hídrica de los Estados, en orden a entregar a un órgano internacional de carácter permanente las potestades necesarias para gestionar de manera holística el ecosistema de cada cuenca compartida, lo que igualmente implicaría la dotación de instrumentos de gestión y de recursos financieros ${ }^{90}$.

Esta preferencia del Derecho Internacional convencional por favorecer el fortalecimiento organizacional a nivel de cuenca encontraría su origen en una multiplicidad de tratados internacionales que, a su vez, contemplan mecanismos generales y especiales de solución de conflictos en la materia ${ }^{91}$. De este modo, se permitiría asegurar de mejor manera la protección del medio ambiente, la aplicación del principio del uso equitativo y razonable de las aguas, así como el acceso a la información y participación, y a la solución de conflictos ${ }^{92}$.

Este principio lleva envuelta la idea de que sólo por medio de una gestión unitaria de la cuenca hidrográfica se podrá garantizar una administración equilibrada, integrada y global de todos los intereses que concurren en los diversos

\footnotetext{
87 Madrazo (2013), p. 39.

88 Salinas (2009), 197.

89 Passos y Delgado (2014), p. 87, y Salinas (2009), p. 201.

90 Passos y Delgado (2014), pp. 99 y 100.

91 Madrazo (2013), p. 58.

92 Passos y Delgado (2014), p. 100.
} 
aprovechamientos existentes. Por ende, el principio de unidad de cuenca hidrográfica requiere la integración de todos los sectores involucrados bajo un marco institucional y operativo único ${ }^{93}$.

En definitiva, cualquier Estado que pretenda una gestión y planificación sustentable de sus recursos hídricos debe estructurar su Derecho de Aguas sobre el principio de unidad de cuenca. De esta manera, la legislación de aguas debe contemplar la existencia de planes hidrológicos de carácter vinculante basados en las características propias de cada cuenca, y prestando consideración especial a los diversos usos que se le den a los recursos hídricos en la cuenca respectiva, así como también a la población que habita dicha superficie territorial. A su vez, los organismos encargados de la gestión de las aguas deben constituirse por cada cuenca hidrográfica, dotados de potestades que les permitan adoptar decisiones de carácter global y unitario en dicho ámbito territorial, restringiéndose únicamente a casos excepcionales y fundados la gestión por tramos o secciones que desconozcan este principio. Asimismo, los organismos de cuenca deben estar integrados por la administración, los usuarios y la sociedad civil, de manera que se asegure la colaboración de todos los actores sociales tendiente a una adecuada gestión de las aguas, evitando la simple distribución de las aguas.

En síntesis, la legislación de aguas debe establecer las disposiciones legales que fortalezcan este principio, de modo que sea la base y la medida de la gestión y la planificación de los recursos hídricos.

\subsubsection{La utilización equitativa y razonable de las aguas, y el principio de prioridad de usos para el consumo humano}

En términos generales, y en conformidad con los principios y reglas del Derecho Internacional, los Estados tienen, por un lado, plena soberanía para explotar sus recursos naturales en cumplimiento de su propia política ambiental y, por otro, el deber de garantizar que dicha explotación no perjudique el medio ambiente de los otros Estados ni a ninguna zona situada fuera de jurisdicción estatal94.

La consagración de la regla del uso equitativo y razonable ${ }^{95}$ en la Convención sobre Cursos de Agua Internacionales constituye un efecto declarativo del principio consuetudinario de carácter general y abstracto según el cual las aguas

93 FAnlo (2010), p. 321.

94 En este sentido, Convenio sobre la Diversidad Biológica (1992), artículo 3.

95 Si bien los usos equitativos y razonables se encuentran estrechamente relacionados, no significan lo mismo. Así, mientras el primero hace referencia a la potestad de un Estado de participar de manera igualitaria en el 
dulces compartidas importan, por una parte, el derecho del Estado ribereño para aprovechar los recursos hídricos que forman parte de su soberanía territorial y, por otra, la obligación de ejercer dicho derecho de manera que el aprovechamiento de las aguas no afecte el derecho de los demás Estados ribereños a utilizar de forma equitativa y razonable las aguas compartidas ${ }^{96}$.

A su vez, dicha convención establece que la utilización equitativa y razonable de los cursos de agua se determinará sobre la base de una serie de factores de diversa índole-como geográficos, sociales, ambientales, hidrográficos, económicos-, que se analizarán conjuntamente, y entre los cuales se encuentra "la población que depende del curso de agua en cada Estado" (artículo 6).

Ahora, el mencionado instrumento internacional contempla la regla general de que ningún uso de un curso de agua internacional tiene en sí mismo una prioridad sobre otros usos, considerándose como excepción algún acuerdo o costumbre en contrario (artículo 10.1). Sin embargo, se dispone que en caso de conflicto entre varios usos en un curso de agua internacional se deberán tener en cuenta de manera especial "las necesidades humanas vitales" (artículo 10.2).

Así, la Corte Internacional de Justicia, en el caso Costa Rica con Nicaragua, ha reconocido la existencia de derechos consuetudinarios de las poblaciones ribereñas sobre los recursos hídricos, cuando éstos sean necesarios para cubrir las necesidades esenciales de la vida diaria ${ }^{97}$.

De esta manera, una interpretación de estas reglas a la luz del principio de buena fe, y especialmente en armonía con el Pidesc y con la mencionada Obligación General No 15, permite entenderlas como una preferencia por aquel uso de los recursos que tenga por finalidad garantizar las necesidades humanas vitales $y$, por ende, el derecho humano al agua y al saneamiento.

\section{Conclusiones}

El motivo por el que la normativa internacional en materia de derechos humanos y medio ambiente debe ser incorporada en la legislación nacional de aguas encuentra su origen conceptual en el hecho de que estos recursos naturales forman parte de la dimensión física del bien jurídico medio ambiente y éste, a su

aprovechamiento del recurso, en relación con los otros Estados, el segundo implica la gestión adecuada del recurso en el ejercicio de las diversas actividades. Arenas (2009), p. 207.

96 Aura y De Medrano (2013), pp. 259 y 260.

97 Corte Internacional de Justicia, Dispute regarding Navigational and Related Rights (Costa Rica con Nicaragua), párrafo 156. 
vez, del entorno global que sirve de base para el pleno goce y ejercicio de una serie de derechos de carácter sustantivo. Así, existe un alto grado de interdependencia, interrelación e indivisibilidad entre las aguas, el medio ambiente y otros derechos humanos, de modo que una adecuada protección de los recursos hídricos no sólo resulta imprescindible para el respeto y garantía de los derechos humanos al agua y a un medio ambiente adecuado, sino también de diversos derechos como la vida, la salud y la libre determinación, entre otros.

De este modo, el Estado se encuentra obligado a configurar su legislación en base a las directrices generales del DIDH, debiendo consagrar y reforzar los derechos humanos procedimentales que por sus características propias permiten una mejor colaboración de la ciudadanía en la toma de decisiones, dando estricto cumplimiento al principio de igualdad y no discriminación. En caso contrario, la sociedad civil podrá activar todos los mecanismos internacionales que le permitan establecer la responsabilidad del Estado por las violaciones a derechos humanos originadas por daños ambientales.

Ahora bien, una correcta integración normativa exige que los Derechos nacionales implementen la norma internacional de manera completa y no parcializada, siendo clave el Derecho de Aguas como rama sectorial, el cual necesariamente deberá configurarse en base a las obligaciones generales del DIDH, a las reglas particulares del derecho humano al agua y al saneamiento, y a los principios del DIMA y del DIA. De esta manera, se revela el estándar del Derecho Internacional para una regulación y protección sustentable de los recursos hídricos, que permita garantizar los distintos derechos humanos involucrados.

En definitiva, los Estados gozan de una amplia autonomía para escoger las medidas que les permitan cumplir de la mejor manera posible con sus obligaciones internacionales; sin embargo, resulta necesario que aquéllos reconozcan cada derecho humano, apliquen los medios necesarios para respetarlos y garantizarlos, y establezcan los mecanismos judiciales y extrajudiciales que posibiliten la tutela efectiva de los mismos por parte de la ciudadanía. En efecto, el Derecho de Aguas debe dar aplicación al principio transversal de igualdad y no discriminación; a los principios de prevención, precaución, acceso a la información, participación pública en la toma de decisiones y acceso a la justicia; al principio de unidad de cuenca hidrográfica, y finalmente al principio de prioridad del uso de las aguas para consumo humano.

\section{BibLIOGRAFÍA CITADA}

Aguilar, Gonzalo (2013): “Gobierno ambiental por consentimiento, participación y evaluación de impacto”, en AA.VV. Evaluación medioambiental, participación 
y protección del medio ambiente. Progresos y retrocesos a la luz de la evolución nacional e internacional (Santiago, Librotecnia), pp. 101-208.

ARENAS, Miguel (2009): "Los principios que regulan la utilización de los acuíferos transfronterizos en los trabajos de la Comisión de Derecho Internacional”, en AA.VV. El agua como factor de cooperación y de conflicto en las relaciones internacionales contemporáneas (Murcia: Instituto Euromediterráneo del Agua), pp. 204-216.

Arístegui, Juan Pablo (2010): "La protección del medio ambiente en la jurisprudencia de algunos órganos internacionales de protección de los derechos humanos", en Justicia Ambiental, (Vol. 2), pp. 23-48.

Aura, Adela y De Medrano, Larios (2013): "La adhesión española a la Convención de Nueva York: consecuencias sobre el vigente régimen de caudales de las cuencas hidrográficas hispano portuguesas", en UTRERA, Sebastián (Dir.), Agua, trasvases y medio ambiente. Las cuencas fluviales y el nuevo plan hidrológico nacional (Madrid, Dykinson), pp. 255-274.

BERMúdEZ, Jorge (2014): Fundamentos de Derecho Ambiental (Valparaíso, Ediciones Universitarias de Valparaíso).

Bonine, John y KRAVCHENKo, Svitlana (2012): “La interpretación de los derechos humanos para la protección del medio ambiente en la Corte Europea de Derechos Humanos", en Justicia Ambiental, (Vol. 4), pp. 73-92.

Borràs, Susana (2014): "Del derecho humano a un medio ambiente sano al reconocimiento de los derechos de la naturaleza", en Revista Vasca de Administración Pública, (No especial 99-100), pp. 649-680.

Bruzón Viltres, Carlos y Antúnez Sánchez, Alcides (2012): "Reflexiones en torno a la protección de los Derechos Humanos desde la perspectiva del Derecho Ambiental Internacional”, en Justicia Ambiental, (Vol. 4), pp. 73-92.

Campusano, Raúl (2014): “Cambio climático y migraciones: Desafíos para el derecho y las políticas públicas”, en Actualidad Jurídica, (Vol. 29), pp. 239-253.

CANÇADO, Antônio (2013): "A proteção de grupos vulneráveis na confluência do direito internacional dos direitos humanos e do direito ambiental internacional", en Aguilar, Gonzalo (Coord.), Evaluación medioambiental, participación y protección del medio ambiente. Progresos y retrocesos a la luz de la evolución nacional e internacional (Santiago, Librotecnia), pp. 267-277.

Carmona, Jorge (2010): "Derechos Humanos y Medio Ambiente", en AA.VV., Derechos Humanos y Medio Ambiente (México DF, Universidad Autónoma de México), pp. 1-34. 
CERSKI, Paula (2011): El derecho ambiental como instrumento de gestión del riesgo tecnológico (Tarragona: Publicaciones URV).

Comisión de Derechos Humanos (1994): Informe final de la Relatora Especial Fatma Zohra Ksentini sobre los Derechos Humanos y el Medio Ambiente, ECN.4/ Sub.2/1994/9, 6 de julio de 1994.

Comisión de Derecho Internacional (2004): Informe final del Relator Especial El Hadji Guissé, Relación entre el disfrute de los derechos económicos, sociales y culturales y la promoción del ejercicio del derecho a disponer de agua potable $y$ servicios de saneamiento, E/CN.4/Sub.2/2004/20, 14 de julio de 2004.

Comisión Interamericana de Derechos Humanos (1997): Informe sobre la Situación de los Derechos Humanos en Ecuador, OEA/Ser.L/V/II.96, 24 de abril de 1997.

Comisión Interamericana de Derechos Humanos (2011): Informe Anual 2010, OEA/Ser.L/V/II, 7 de marzo de 2011.

Comité de Derechos Económicos, Sociales y Culturales (1999): Observación general $N^{o}$ 12. El derecho a una alimentación adecuada (artículo 11 del Pacto Internacional de Derechos Económicos, Sociales y Culturales), E/C.12/1999/5.

Comité de Derechos Económicos, Sociales y Culturales (2000): Observación general $N^{o} 14$. El derecho al disfrute del más alto nivel posible de salud (artículo 12 del Pacto Internacional de Derechos Económicos, Sociales y Culturales), E/C.12/2000/4.

Comité de Derechos Económicos, Sociales y Culturales (2003): Observación general $N^{o}$ 15. El derecho al agua (artículos 11 y 12 del Pacto Internacional de Derechos Económicos, Sociales y Culturales), E/C.12/2002/11.

Comité de Derechos Económicos, Sociales y Culturales (2010): Statement on the Right to Sanitation, E/C.12/2010/1.

Consejo de Derechos Humanos (2012): Informe preliminar del Experto independiente John H. Knox sobre la cuestión de las obligaciones de derechos humanos relacionadas con el disfrute de un medio ambiente sin riesgos, limpio, saludable y sostenible, A/HRC/22/43, 24 de diciembre de 2012.

CourTis, Christian (2007): Derechos sociales, ambientales y relaciones entre particulares (Bilbao, Universidad de Deusto).

Earthjustice (2008): Environmental Right Report 2008: Human Rights and the Environment (Oakland, Earthjustice).

Embid Tello, Antonio (2010): Precaución y Derecho: el caso de los campos electromagnéticos (Madrid, Iustel). 
EsPINOZA, Patricio (2010): "El derecho fundamental a vivir en un medio ambiente libre de contaminación como derecho social”, en Revista de Derecho Público, (Vol. 73), pp. 171-192.

FANLO, Antonio (2007): La Unidad de gestión de las cuencas hidrográficas: estudios y dictámenes jurídico-administrativos (Murcia, Instituto Euromediterráneo del Agua).

FANLO, Antonio (2010): "Las competencias del Estado y el principio de unidad de gestión de cuenca a través de las confederaciones hidrográficas", en Revista de Administración Pública, (No 183), pp. 309-334.

FERnÁNDEZ, Rosa (2013): "Jurisprudencia ambiental internacional”, [fecha de consulta: 18 de diciembre de 2016]. [Disponible en: http://www.rcda.cat/ index.php/rcda/article/viewFile/444/2155].

Ferreira de Carvalho, Edson (2008): "La contribución del derecho humano a la protección ambiental: integrar para mejor cuidar la tierra y la humanidad", en American University International Law Review, (Vol. 24), pp. 141-180.

Fuentes, Ximena y Arístegui, Juan Pablo (2014): “¿Nos basta con los convenios internacionales existentes para una adecuada regulación del uso sustentable de los recursos naturales?", en AA.VV., Actas de las VII Jornadas de Derecho Ambiental. Recursos naturales ¿Sustentabilidad o sobreexplotación? (Santiago, Thomson Reuters), pp. 65-103.

Guzmán, Rodrigo (2012): Derecho Ambiental chileno. Principios, instituciones, instrumentos de gestión (Santiago, Planeta Sostenible).

Harrison, James (2013): "Reflections on the role of International Courts and Tribunals in the settlement of environmental disputes and the development of International Environmental Law", en Journal of Environmental Law (Vol. 25, No 3), pp. 501-514.

Hervé, Dominique (2013): “Noción y elementos de justicia ambiental: directrices para su aplicación en la planificación territorial y en la evaluación ambiental estratégica”, en AA.VV., Justicia ambiental, derecho e instrumentos de gestión del espacio marino costero (Santiago, Lom), pp. 9-36.

JARIA, Jordi (2011): La cuestión ambiental y la transformación de lo público (Valencia, Tirant lo Blanch).

Kirschner, Adele (2011): “The human right to water and sanitation”, en Maz Planck Yearb UN Law, (No 15), pp. 445-487.

LASKOWSKI, Ruth (2012): “Time for Implementation of the Right to Water and Sanitation-eg The Missing Implementation in Germany", en Journal for European Environmental \& Planning Law, (Vol. 9, No 2), pp. 164-179. 
LEWIS, Bridget (2012): "Environmental Rights or a Right to the Environment? Exploring the Nexus Between Human Rights and the Environmental Protection", en Macquarie Journal of International and Comparative Environmental Law, (Vol. 8, No 1), pp. 36-47.

Llanos, Hugo (2007): Teoría y práctica del Derecho Internacional Público (Santiago, Editorial Jurídica), tomo II, Vol.1.

Madrazo, Enrique (2013): "La regulación internacional de los ríos: el carácter axial del concepto de cuenca fluvial", en Utrera, Sebastián (Dir.), Agua, trasvases y medio ambiente. Las cuencas fluviales y el nuevo plan hidrológico nacional (Madrid, Dykinson), pp. 35-64.

Martínez Pérez, Enrique (2013): "Sentencia del TEDH de 18 de junio de 2013, demanda No 0474/08, Bor contra Hungría”, en Actualidad Jurídica Ambiental, (Vol. 7), pp. 1-5.

Martín-Retortillo, Lorenzo (2008): "Jurisprudencia ambiental reciente del Tribunal Europeo de Derechos Humanos", en Revista española de Derecho Administrativo, (No 140), pp. 781-807.

Mitre, Eduardo (2012): El derecho al agua. Naturaleza jurídica y protección legal en los ámbitos nacionales e internacionales (Madrid, Iustel).

Ortega, Daniela y Larraín, Cristóbal (2012): "El derecho a vivir en un medio ambiente sano", en AGUILAR, Gonzalo (Coord.), Derechos económicos, sociales y culturales en el orden constitucional chileno (Santiago, Librotecnia), pp. 519-547.

Passos, Viviane y Delgado Francisco (2014): "Algunas reflexiones sobre la gestión integrada de las cuencas hidrográficas compartidas", en BENITO, Miguel (Dir.), Agua y Derecho, retos para el siglo XXI (Alicante, Thomson Reuters Aranzadi), pp. 85-103.

Pigrau, Antoni y Borràs, Susana (2008): "Diez años del Convenio Aarhus sobre el acceso a la información, la participación, y el acceso a la justicia en materia del medio ambiente", en AA.VV., Acceso a la información, participación pública $y$ acceso a la justicia en materia de medio ambiente: diez años del Convenio de Aarhus (Barcelona, Atelier), pp. 21-83.

Ríos, Marcos (2014): "La configuración del derecho al medio ambiente adecuado como derecho procedimental", en Borràs, Susana (Dir.), Derecho internacional y comparado del medio ambiente: temas actuales (Barcelona, Huygens), pp. 37-74.

RÜegger, Vanessa (2014): "Water Distribution in the Public Interest and the Human Right to Water: Swiss, South African and International Law Compared", en Law, Environment and Development Journal, (No 10), pp. 1-34. 
SAlinas, Sergio (2009): "La cuenca hidrográfica en el Derecho Internacional de los recursos hídricos", en AA.VV., El agua como factor de cooperación y de conflicto en las relaciones internacionales contemporáneas (Murcia: Instituto Euromediterráneo del Agua), pp. 193-201.

SALmón, Elizabeth (2012): "El derecho humano al agua y los aportes del Sistema Interamericano de Derechos Humanos", en Revista de Filosofía, Derecho y Politica (No 16), pp. 245-268.

SAURA, Jaume (2012): "El derecho humano al agua potable y al saneamiento en perspectiva jurídica internacional", en Derechos y Libertades: Revista del Instituto Bartolomé de las Casas, (Vol. 16, No 26), pp. 145-180.

Serrano Tur, Lidia (2014): Aguas dulces y Derecho internacional: el agua como bien común y como derecho humano desde la perspectiva del desarrollo sostenible (Barcelona, Huygens).

Shelton, Dinah (2010): "Derechos ambientales y obligaciones en el sistema interamericano de derechos humanos", en Anuario de Derechos Humanos, Universidad de Chile (No 6), pp. 111-127.

Simón, Fernando (2010): "La construcción de la tutela ambiental en la jurisprudencia de Estrasburgo", en Persona y Derecho, (Vol. 63), pp. 87-110.

VERNET, Jaume y JARIA, Jordi (2007): "El derecho a un medio ambiente sano: su reconocimiento en el constitucionalismo comparado y en el derecho internacional", en Teoría y Realidad Constitucional, (No 20), pp. 513-533.

Zander, Joakim (2010): The Application of the Precautionary Principle in Practice (Cambridge, University Press).

\section{NORMAS JURÍDICAS CITADAS}

Convenio Europeo para la Protección de los Derechos Humanos y de las Libertades Fundamentales, adoptado por el Consejo de Europa, el 4 de noviembre de 1950, entrada en vigencia el 3 de septiembre de 1953.

Pacto Internacional de Derechos Económicos, Sociales y Culturales, adoptado por la Asamblea General de las Naciones Unidas por Resolución No 2200 A (XXI), de 16 de diciembre de 1966, entrada en vigencia el 3 de enero de 1976.

Convención Americana de Derechos Humanos, adoptada por la Organización de Estados Americanos, el 22 de noviembre de 1969, entrada en vigencia el 18 de julio de 1978.

Declaración de la Conferencia de las Naciones Unidas sobre Medio Humano, adoptada en Estocolmo, 5 al 16 de junio de 1972. 
Declaración de la Conferencia de Naciones Unidas sobre el Agua, adoptada en Mar del Plata, 7 al 18 de marzo de 1977.

Convención sobre la Eliminación de todas las Formas de Discriminación contra la Mujer, adoptada por la Asamblea General de Naciones Unidas el 18 de diciembre de 1979, entrada en vigencia 3 de septiembre de 1981.

Convenio No 169 sobre Pueblos Indígenas y Tribales en Paises Independientes, adoptado por la Organización Internacional del Trabajo el 27 de junio de 1989, entrada en vigencia 6 de septiembre de 1991.

Convención sobre los Derechos del Niño, adoptada por la Asamblea General de las Naciones Unidas el 20 de noviembre de 1989, entrada en vigencia el 2 de septiembre de 1990.

Declaración de la Conferencia Internacional sobre Agua y Medio Ambiente, adoptada en Dublín, del 26 al 31 de enero de 1992.

Declaración de Río sobre el Medio Ambiente y el Desarrollo, adoptada en la Conferencia de las Naciones Unidas sobre el Medio Ambiente y el Desarrollo celebrada en Río de Janeiro del 3 al 14 de junio de 1992. Aprobada por la Asamblea General el 12 de agosto de 1992.

Declaración de la Conferencia Internacional sobre el Agua Dulce, adoptada en Bonn el 4 de diciembre de 2001.

Convenio sobre la Diversidad Biológica, adoptado en la Conferencia de Naciones Unidas sobre Medio Ambiente y Desarrollo, realizada en Río de Janeiro, 3 al 14 de junio de 1992. Entrada en vigencia el 29 de diciembre de 1993.

Convención Marco de las Naciones Unidas sobre el Cambio Climático, adoptada el 9 de mayo de 1992, entrada en vigencia 21 de marzo de 1994.

Convención de Lucha Contra la Desertificación a los Paises Afectados por la Sequía Grave y/o la Desertificación, en Particular África, adoptada el 17 de junio de 1992, entrada en vigencia 26 de diciembre de 1996.

Declaración de la Conferencia Mundial de Derechos Humanos, adoptada en la Conferencia Mundial de Derechos Humanos, realizada en Viena, 14 a 25 de junio de 1993, aprobadas por la Conferencia Mundial de Derechos Humanos el 25 de junio de 1993.

Convención de Naciones Unidas sobre el derecho de los usos de los cursos de agua internacionales para fines distintos de la navegación, adoptada por la Asamblea General de Naciones Unidas el 8 de julio de 1997, entrada en vigencia 17 de agosto de 2014.

Convenio sobre Acceso a la Información, la Participación del Público en la Toma de Decisiones y el Acceso a la Justicia en Materia de Medio Ambiente, adoptado 
por la Comisión Económica para Europa el 25 de junio de 1998, entrada en vigencia 30 de octubre de 2001.

Directiva 2000/60/CE del Parlamento Europeo y del Consejo de la Unión Europea, por la que se establece un marco comunitario de actuación en el ámbito de la política de aguas, de 23 de octubre de 2000.

Protocolo de la Carta Africana de Derechos Humanos y de los Pueblos sobre los Derechos de la Mujer en África, adoptado por la Asamblea de la Unión Africana el 11 de julio de 2003, entrada en vigor 25 de noviembre de 2005.

D.F.L. No 100 de 2005, del Ministerio Secretaría General de la Presidencia. Fija el texto refundido, coordinado y sistematizado de la Constitución Política de la República de Chile. Diario Oficial, 22 de septiembre de 2005.

Convención Internacional sobre los Derechos de las Personas con Discapacidad, adoptada por la Asamblea General de Naciones Unidas el 13 de diciembre de 2006, entrada en vigencia 12 de mayo de 2008.

Declaración de Naciones Unidas sobre Derechos de los Pueblos Indígenas, adoptada por la Asamblea General de las Naciones Unidas el 13 de septiembre de 2007. Resolución sobre el derecho humano al agua y el saneamiento, A/64/L.63/ Rev.1, adoptada por la Asamblea General de las Naciones Unidas el 28 de julio de 2010. Convención Interamericana sobre la Protección de los Derechos Humanos de las Personas Mayores, adoptada por la Asamblea General de Estados Americanos, el 15 de junio de 2015.

\section{JURISPRUDENCIA CITADA}

López Ostra con España (1994): Tribunal Europeo de Derechos Humanos, Sentencia 9 de diciembre de 1994.

Horvath Kiss y otros con Comisión Nacional del Medio Ambiente (1997): Corte Suprema, 19 de marzo de 1997 (recurso de protección), en: Revista de Derecho y Jurisprudencia, Tomo XCIV, 2a parte, secc. $5^{\mathrm{a}}$.

Hungría con Eslovaquia (1997): Corte Internacional de Justicia, 25 de septiembre de 1997. Caso Gabcikovo-Nagymaros.

Guerra y otros con Italia (1998): Tribunal Europeo de Derechos Humanos, Sentencia 19 de febrero de 1998.

Hatton y otros con Reino Unido (2001): Tribunal Europeo de Derechos Humanos, Sentencia 2 de octubre de 2001.

Comunidades Indígenas Mayas del Distrito de Toledo con Belice (2004): Comisión Interamericana de Derechos Humanos, Informe de Fondo, 12 de octubre de 2004. 
Fadeyeva con Rusia (2005): Tribunal Europeo de Derechos Humanos, Sentencia 9 de junio de 2005.

Costa Rica con Nicaragua (2005): Corte Internacional de Justicia, 29 de septiembre de 2005. Caso Dispute regarding Navigational and Related Rights.

Claude Reyes y otros con Chile (2006): Corte Interamericana de Derechos Humanos (Fondo, reparaciones y costas), Sentencia 19 de septiembre de 2006.

Pueblo Saramaka con Surinam (2007): Corte Interamericana de Derechos Humanos (Excepciones preliminares, fondo, reparaciones y costas), Sentencia 28 de noviembre de 2007.

Tatar con Rumanía (2009): Tribunal Europeo de Derechos Humanos, Sentencia 27 de enero de 2009.

Miguel Ignacio Fredes González y Ana Andrea Tuczek Fries con Chile (2009): Comisión Interamericana de Derechos Humanos, Informe de Admisibilidad, 19 de marzo de 2009.

Comunidades Indigenas Ngöbe y sus miembros en el valle del río Changuinola con Panamá (2009): Comisión Interamericana de Derechos Humanos, Informe de Admisibilidad, 5 de agosto de 2009.

Grupo de Tratado Hul'quminum con Canadá (2009): Comisión Interamericana de Derechos Humanos, Informe de Admisibilidad, 30 de octubre de 2009.

Comunidad Agrícola Diaguita de los Huascoaltinos y sus miembros con Chile (2009):

Comisión Interamericana de Derechos Humanos, Informe de Admisibilidad, 30 de diciembre de 2009.

Mossville Environmental Action con Estados Unidos (2010): Comisión Interamericana de Derechos Humanos, Informe de Admisibilidad, 17 de marzo de 2010. Comunidad Indígena Xakmok Kásek con Paraguay (2010): Corte Interamericana de Derechos Humanos (Fondo, reparaciones y costas), Sentencia 24 de agosto de 2010.

Dubetska y otros con Ucrania (2011): Tribunal Europeo de Derechos Humanos, Sentencia 10 de febrero de 2011.

Navarro Brain y otros con Congreso Nacional (2011): Tribunal Constitucional 24 de junio de 2011 (requerimiento de inaplicabilidad por inconstitucionalidad). Bor con Hungría (2013): Tribunal Europeo de Derechos Humanos, Sentencia 18 de junio de 2013.

Luna López con Honduras (2013): Corte Interamericana de Derechos Humanos (Fondo, reparaciones y costas), Sentencia 10 de octubre de 2013. 